\title{
DiVERSIDADE SEXUAL E DE GÊNERO, \\ ESTADO NACIONAL E PAISAGENS \\ HETEROTÓPICAS NO IRÃ: \\ FOUCAULT E DEPOIS
}

Fabiano Gontijo (D)

Universidade Federal do Pará

1 os noticiários brasileiros e ocidentais em geral, as poucas informações sobre a República Islâmica do Irã abordam as pretensões armamentistas do "regime dos aiatolás" - geralmente associadas de forma inconclusiva a uma espécie de cruzada religiosa fundamentalista - que motivaram a imposição de sanções e embargos comerciais por parte dos países mais ricos. Com o alinhamento da grande mídia brasileira às agências de informação estadunidenses e europeias, o orientalismo "saidiano" se torna a marca dessas notícias, grande parte delas focadas na denúncia da violação dos direitos humanos resultante das políticas do regime acusadas de repressivas. ${ }^{1}$

A evocação do Irã parece exercer um estranho sentimento sobre as pessoas: as lembranças do passado glorioso do Império Persa (ou Aquemênida) retratado em nossos livros de história, marcado pela grandiosidade territorial, a arquitetura e o urbanismo monumentais, contrapõem-se às imagens veiculadas na esteira do discurso do presidente Bush após os eventos de 11 de setembro de 2001, quando cunhou a expressão “eixo do mal” referindo-se aos países que supostamente possuíam armas

1 Agradeço ao Conselho Nacional do Desenvolvimento Científico e Tecnológico pela bolsa de produtividade em pesquisa. Agradeço, ainda, Rosa Elizabeth Acevedo Marín (Universidade Federal do Pará) e Igor Erick (Universidade Federal do Pará) pelas leituras e comentários preciosos. 
de destruição em massa a serviço do terrorismo, como o Irã e outros de maioria muçulmana, além da Coreia do Norte. ${ }^{2}$

Não se trata aqui de propor uma análise exaustiva da conjuntura social, política e econômica atual do Irã, na forma de uma monografia, mas de indicar pistas de reflexão etnográfica sobre alguns temas relacionados à vida na contemporaneidade, em particular a relação entre, de um lado, a elaboração simbólica e a manutenção prática da identidade nacional, da ideologia de nation-building e do nacionalismo - necessários para a sustentação das políticas do Estado e para a conservação do governo islâmico -, e de outro, as experiências da diversidade sexual e as performances de gênero - comumente relacionadas nos noticiários ocidentais, quase não sem razão, à criminalização da homossexualidade com a aplicação da pena capital para pessoas acusadas de sodomia e às restrições às liberdades individuais das mulheres.

Partirei dos relatos produzidos por Michel Foucault sobre os eventos de 1978-1979 que culminaram com a deposição do último monarca, a ascensão do líder religioso Khomeini e a proclamação da República Islâmica, tudo isso em um processo conhecido como Revolução Iraniana. ${ }^{3}$ Em suas análises, baseadas em duas viagens ao Irã realizadas em setembro e novembro de 1978 a serviço do diário Corriere della Sera, o filósofo acreditava que o processo revolucionário parecia ir de encontro à modernidade ocidental (que, até certo ponto, caracterizava a forma de governo monárquica vigente) ao se caracterizar por uma espécie de "espiritualidade política” e que, passado o período de turbulência, as forças seculares retomariam as rédeas do governo, agora sobre bases democráticas críticas à modernidade ocidental. Mas, o que se viu de fato foi a instauração de um sistema de governo teocrático, a perseguição dos membros dos movimentos de esquerda e a limitação das liberdades individuais, em particular das mulheres e de homossexuais.

2 George W. Bush, “The President's State of the Union Address, 29 jan. 2002”, The White House: President George W. Bush 巴.

3 Usarei a grafia Imam Khomeini, embora haja outras. 
Em seguida, esboçarei uma reflexão sobre o impacto da "espiritualidade política” no período pós-revolucionário na construção de um Estado nacional com regimes de verdade, tecnologias de poder/saber e dispositivos biopolíticos geradores de distopias e conformadores de uma ideologia nacional teocrática preocupada com o controle dos corpos e com a imposição da heteronormatividade. Tratarei dos modos originais de resistência ao regime de verdade vigente e de produção de formas de subjetivação alternativas, principalmente no que diz respeito às experiências da diversidade sexual e de gênero. Esses modos alternativos parecem compor "heterotopias" desafiadoras das distopias reinantes, como sugerido por minha experiência de observações etnográficas e conversas guiadas realizadas em quatro cidades iranianas em fevereiro de 2019.

Mas, em que poderia um antropólogo brasileiro contribuir para as reflexões sobre a diversidade sexual e as performances de gênero em sua relação com a ideologia de nation-building no Irã, diante das pesquisas já existentes feitas por iranianas/os e outras/os? ${ }^{4}$

Uma das marcas das antropologias latino-americanas é a relação entre a produção teórica das/os antropólogas/os e o seu compromisso com as sociedades estudadas, já que também participam, nessa região, junto com suas/seus interlocutoras/es, do processo de construção nacional por meio da luta pela democracia e contra a situação colonial e as formas de colonialismos internos. ${ }^{5}$ Jimeno sugere que o naciocentrismo da antropologia latino-americana (a relação entre os conceitos e as condições sociais em que foram produzidos) sempre teve por missão, em sua grande parte, o questionamento das bases ideológicas do Estado-nação e da situação

4 Association for Iranian Studies, Iranian Studies ש; Middle East Studies Association, International Journal of Middle East Studies 〔 . Há um número reduzido de pesquisas sobre as relações entre experiências da diversidade sexual e expressões de gênero, de um lado, e Estado e processos de construção de nação, de outro.

5 Pablo González Casanova, “Colonialismo Interno (Una Redefinición)” in Atilio Boron, Javier Amadeo e Sabrina González (orgs.), La Teoria Marxista Hoy (Buenos Aires: CLACSO, 2006), pp. 409-434; Esteban Krotz, "La Generación de Teoría Antropológica em América Latina: silenciamientos, tensiones intrínsecas y puntos de partida”, Maguaré, n. 11-12 (1996), pp. 25-39 ש. 
colonial persistente $-{ }^{6}$ o que é confirmado também por Das, no que se refere ao contexto indiano, e Mafeje e Ela, com relação ao contexto africano. ${ }^{7}$ Acredito que o cumprimento dessa missão pode contribuir para a instrumentalização de um fazer antropológico transnacional potencialmente decolonial que justifique um estudo brasileiro sobre as relações entre Estado e sexualidade no Irã. ${ }^{8}$

O Estado-nação europeu moderno, com os seus dispositivos disciplinares bionecropolíticos de governamentalidade, impôs-se ao longo dos séculos XIX e XX como uma máquina objetiva de guerra (ideológica, mas não somente) que tem no controle dos corpos, na reelaboração das discursividades de gênero e na autoridade sobre as práticas sexuais alguns dos seus principais alvos reais. ${ }^{9}$

Assim, informado pelos mecanismos que estão na base da colonialidade do poder/saber estruturadores da situação colonial e dos colonialismos internos ${ }^{10}$ e consciente do potencial heurístico desprovincializador do fazer antropológico do ponto de vista do Sul Global, ${ }^{11}$

6 Myriam Jimeno Santoyo, "Naciocentrismo: tensiones y configuración de estilos en la antropología sociocultural colombiana”, Revista Colombiana de Antropología, n. 43 (2007), pp. 9-32 ש.

7 Veena Das, Critical Events. An Anthropological Perscpective on Contemporary India, New Delhi: Oxford University Press, 1998; Archie Mafeje, “A Commentary on Antrhropology and Africa”, Codesria Bulletin, n. 3-4 (2008), pp. 88-94 ש; Jean-Marc Ela, Recherche Scientifique et Crise de la Rationalité, Paris: L'Harmattan, 2007, v. 1.

8 Edgardo Lander (org.), A colonialidade do saber, Buenos Aires: CLACSO, 2005.

9 Sobre a fusão da biopolítica de Foucault com a necropolítica de Mbembe, cf. Fátima Lima, "Bio-Necropolítica", Arquivos Brasileiros de Psicologia, v. 70, n. spe. (2017), pp. 20-33. Michel Foucault, Sécurité, Territoire, Population. Cours au Collège de France (1977-1978), Paris: Gallimard; Seuil, 2004; e Naissance de la Biopolitique. Cours au Collège de France (1978-1979), Paris: Gallimard; Seuil, 2004; Achille Mbembe, Necropolítica, São Paulo: n-1 Edições, 2018.

10 Roberto Cardoso de Oliveira, "O movimento dos conceitos na antropologia”, Revista de Antropologia, n. 36 (1993), pp. 13-31 ש; Myriam Jimeno Santoyo, "La vocación crítica de la antropología latinoamericana”, Maguaré, n. 18 (2004), pp. 33-58 ש; Lander (org.), A colonialidade do saber.

11 Dipesh Chakrabarty, Provincializing Europe, Princeton: Princeton University Press, 2007; Mafeje, "A Commentary on Anthropology and Africa"; Eduardo Restrepo e Arturo Escobar, “'Other Anthropologies and Anthropology Otherwise': Steps to a World Anthropologies Framework”, Critique of Anthropology, v. 25, n. 2 (2005), pp. 99-129 600. 
um antropólogo brasileiro pode propor uma análise, como aquela que esboçarei a seguir, das formas de resistência criativa aos saberes, discursos, práticas e poderes disciplinares religiosos, médicos e jurídicos que se desenvolveram ao longo dos últimos quarenta anos no Irã, após a passagem de Foucault por lá.

Enfim, estaremos aptos a compreender a maneira como o projeto de governamentalidade instituidor do Estado-nação em vigor naquele país abriu brechas para formas interessantes de heterotopias que estariam, atualmente, minando o empreendimento de nation-building. Isso pode nos ajudar a refletir sobre os modos de funcionamento, na contemporaneidade, dos processos transnacionais de instauração de hegemonias ideológicas caracterizadas por formas naturalizadas de sexismos, heteronormatividade, racismos, classismos, fundamentalismos religiosos, conservadorismos políticos, ou seja, pela situação colonial e a colonialidade, além das diversas reações anti- e contra-hegemônicas consequentes.

\section{Foucault no Irã}

Comecei a viagem ao Irã por Isfahan, a cidade mais visitada do país, no dia 8 de fevereiro de 2019. No dia seguinte a minha chegada, antevéspera da comemoração dos quarenta anos da revolução, no quarto do hotel onde eu estava hospedado e enquanto zapeava pelos poucos canais de televisão disponíveis - todos estatais -, eis que, para a minha surpresa, em meio a programas que só tratavam da revolução, um documentário exibia imagens de... Michel Foucault. O documentário era em persa e todas as vezes em que ele aparecia, a sua voz era dublada. Imagens das manifestações nas ruas do país durante o processo revolucionário, capas de livros e aparições do filósofo se intercalavam com trechos de entrevistas de aiatolás e membros do clero, homens engravatados e o próprio Foucault.

Curioso, fui até o lobby do hotel e pedi ao recepcionista que sintonizasse a televisão naquele canal e me dissesse do que se tratava. 
Ao aparecer a imagem de Foucault, ele disse: "Ah! É um francês, um homem bom, um herói da revolução”. Diante da minha expressão de espanto, repetiu: "Um homem realmente bom, um herói”. ${ }^{12}$ Ele tentou resumir o tema do documentário, que apresentava Foucault como o exemplo de intelectual internacional que tinha entendido que o momento revolucionário fora muito importante para o mundo, pois o Irã desafiava o Ocidente. Não conseguia entender, naquele momento, como os escritos de Foucault sobre o Irã teriam-no içado a herói - um ocidental, homossexual e vítima da aids. Para entender a presença de Foucault no Irã, os relatos publicados e a controvérsia consequente, proponho uma breve incursão pela história do país e da relação do xiismo-islamismo com o Estado, desembocando no período revolucionário do final da década de $1970 .{ }^{13}$

Até os dias de hoje, uma tensão se apresenta entre a percepção que se tem do passado persa pré-islâmico e a era inaugurada a partir do século VII, alimentando discussões sobre os ganhos e as perdas da islamização e sobre a própria raiz da identidade nacional iraniana. ${ }^{14}$ Alguns autores tratam, por exemplo, da maneira como tradições pré-islâmicas teriam perdurado até os dias de hoje e/ou sido assimiladas pelo islamismo, conformando a identidade iraniana, ${ }^{15}$ apesar das peculiaridades do expansionismo islâmico muitas vezes marcado pela guerra santa ou jihad. ${ }^{16}$

Com a dinastia Safávida, a partir do século XVI, o xiismo deixava de ser uma seita perseguida e se tornava a religião oficial, pela primeira vez, num território dominado por muçulmanos. ${ }^{17}$ As dinastias que reinaram até

12 Os trechos de falas das pessoas com as quais conversei, além de todos as partes de textos lidos em francês ou inglês e citadas aqui, serão traduzidos livremente para o português e inseridas no corpo do texto sem os originais em língua estrangeira.

13 Usarei Islã e islamismo para designar a religião.

14 Para entender melhor o islamismo e as relações entre religião e poder, cf. Pascal Buresi, “Histoire de l’Islam”, La Documentation photographique, n. 8058 (2007), pp. 2-66; Gabriele Marranci, The Anthropology of Islam, Oxford: Berg, 2008.

15 Fereshteh Davaran, Continuity in Iranian Identity, London: Routledge, 2010.

16 Liyakat N. Takim, The Heirs of the Prophet: Charisma and Authority in Shi'ite Islam, Albany: State University of New York Press, 2006.

17 As interpretações dos discursos do Profeta Maomé e as disputas acerca da liderança religiosa e política após a sua morte levaram ao desenvolvimento de diversas vertentes, 
o início do século XX, mesmo tendo adotado o islamismo como religião oficial, conservaram muitos aspectos dos modos de vida pré-islâmicos, criando uma sociedade xiita liderada pelo "xá” que se opunha ao sunismo encarnado pelo poderoso Império Otomano. ${ }^{18}$

A Pérsia se tornou um importante centro de irradiação de conhecimentos (científicos e tecnológicos), produção artística e certa liberdade de expressão de gênero e da diversidade sexual. Por isso, despertou a atenção de potências europeias no século XIX, principalmente a Rússia e o Reino Unido, ${ }^{19}$ encantadas com as belezas de suas cidades e com a produção de obras de arte e literárias - estas trazendo relatos explícitos de práticas sexuais entre pessoas do mesmo sexo/gênero, relativamente corriqueiras nesse período, para espanto dos europeus então submetidos a discursos heteronormativos médico-científicos. ${ }^{20}$

Assim começava a história moderna iraniana, tendo como características a sua inserção paulatina no jogo de poder dos Estados nacionais europeus por um lado e, por outro, o seu desejo de liderar o mundo muçulmano - contra o Império Otomano, no passado e, mais recentemente, contra a Arábia Saudita. ${ }^{21}$ Com a crescente influência europeia entre os séculos XIX e XX, dividindo o país em zonas de influência britânica e russa, comerciantes locais dos bazares passaram a demonstrar o seu descontentamento em relação às vantagens concedidas pelos governantes aos produtos manufaturados europeus. ${ }^{22} \mathrm{O}$ descontentamento aumentou

dentre as quais as mais numerosas são a sunita (majoritária, encabeçada hoje pela Arábia Saudita) e a xiita (liderada sobretudo pelo clero iraniano).

18 Homa Katouzian, The Persians: Ancient, Medieval and Modern Iran, New Haven: Yale University Press, 2009.

19 Stephanie Cronin (org.), Iranian-Russian Encounters: Empires and Revolutions Since 1800, Londres: Routledge, 2013; Homa Katouzian, Iranian History and Politics: The Dialectic of State and Society, Londres: Routledge, 2003.

20 Willem Floor, A Social History of Sexual Relations in Iran, Washington: Mage Publishers, 2008; Katouzian, The Persians; Afsaneh Najmabadi, Women With Mustaches and Men Without Beards: Gender and Sexual Anxieties of Iranian Modernity, Berkeley: University of California Press, 2005.

21 Ervand Abrahamian, A History of Modern Iran, Cambridge: Cambridge University Press, 2008.

22 Cronin, Iranian-Russian Encounters; Katouzian, The Persians. 
depois que o controle de praticamente todos os instrumentos e recursos econômicos lucrativos foi concedido a um empreendedor britânico em troca de parte reduzida dos lucros para o financiamento dos gastos dos monarcas. Os comerciantes conseguiram o apoio do clero - responsável pelas escolas, prestações de assistência social e até cortes judiciárias -, que emitiu uma fatwa criminalizando o uso de tabaco..$^{23} \mathrm{O}$ monarca cedeu, mas estava consumada a oposição entre o governo, de um lado e, de outro, parte dos comerciantes e do campesinato e, sobretudo, o clero xiita, o que marcaria todo o século XX e abriria o caminho para a revolução na década de $1970 .^{24}$

A Revolução Constitucionalista que se seguiu no início do século XX impôs à monarquia uma constituição e um parlamento. ${ }^{25}$ Para pôr fim à instabilidade persistente, um golpe de Estado findou a dinastia Qajar e, em 1925, Reza Shah, um militar, foi entronizado, iniciando a dinastia Pahlavi. Durante os seus 16 anos de reinado, a Pérsia se tornou Irã - contra a histórica designação grega - e a modernização no estilo europeu se consolidou, inclusive, com a exploração do petróleo concedida aos britânicos. ${ }^{26}$ Para maior descontentamento do clero, as mulheres foram proibidas de usar o véu e o xá tentou se aproximar das minorias religiosas e étnicas e do campesinato, com o intuito de forjar uma identidade nacional plural e também passou a condenar as práticas sexuais entre pessoas do mesmo

23 Aiatolá (“sinal de Deus”) é um dos títulos mais elevados outorgados a um membro do clero xiita. Comparativamente ao clero sunita, o xiita é extremamente hierarquizado e o aiatolá corresponde a um doutor que produz conhecimentos com valor de lei, baseados nos textos sagrados, na jurisprudência e nas suas experiências espirituais, sobre ética e moralidade, filosofia, misticismo e as coisas da vida individual e social em geral. O aiatolá tem o direito de emitir fatwa, ou seja, uma opinião que tem valor de lei sobre uma questão qualquer.

24 Stephanie Cronin (org.), The Making of Modern Iran: State and Society Under Riza Shah (1921-1941), Londres: Rouledge, 2005; Vanessa Martin, Iran Between Islamic Nationalism and Secularism, Londres: I. B. Tauris, 2013.

25 Janet Afary, The Iranian Constitutional Revolution, 1906-1911: Grassroots Democracy, Social Democracy, and the Origins of Feminism, Nova York: Columbia University Press, 1996; Katouzian, Iranian History and Politics; Martin, Iran Between Islamic Nationalism and Secularism.

26 Cronin (org.), The Making of Modern Iran. 
sexo ou gênero, vistas agora como patológicas e anti-modernas, posto que representativas do passado. ${ }^{27}$

Em 1951, o primeiro-ministro alinhado à esquerda nacionalizou a produção de petróleo, o que levou ao boicote do produto iraniano e a um confronto com Reza Pahlavi, que abandonou o país. Em 1953, um golpe de Estado reconhecidamente organizado pelos Estados Unidos e o Reino Unido depôs o primeiro-ministro e permitiu a volta do xá. ${ }^{28}$ A partir desse momento, o país seria marcado, por um lado, por uma economia em grande parte voltada para os interesses estadunidenses, pela militarização financiada pelos Estados Unidos, pela violência contra toda e qualquer forma de oposição política por meio da polícia secreta e pela corrupção, ${ }^{29}$ e, por outro, pela continuação da ocidentalização da vida social - como a concessão do direito de voto às mulheres e o reforço da proibição do uso do véu -, principalmente na década de 1960, com uma série de reformas sociais, econômicas e políticas modernizantes objetivando abranger uma reforma agrária que acabou, de fato, por incrementar o poder (e a corrupção) das camadas médias urbanas ocidentalizadas; ${ }^{30}$ e, enfim, pela crescente oposição ao mundo árabe sunita, avigorada pela valorização

27 Houchang E. Chehabi, “Staging the Emperor's New Clothes: Dress Codes and NationBuilding Under Reza Shah”, Iranian Studies, v. 26, n. 3-4 (1993), pp. 209-233 ש; Cronin (org.), The Making of Modern Iran; Stephanie Cronin, Tribal Politics in Iran: Rural Conflict and the New State (1921-1941), Londres: Routledge, 2007; Wendy DeSouza, Unveiling Men: Modern Masculinities in Twentieth-Century Iran (Gender, Culture, and Politics in the Middle East), Syracuse: Syracuse University Press, 2019; Najmabadi, Women With Mustaches and Men Without Beards; Hamideh Sedghi, Women and Politics in Iran: Veiling, Unveiling, and Reveiling, Cambridge: Cambdridge University Press, 2007.

28 Eskandar Sadeghi-Boroujerdi, Revolution and Its Discontents: Political Thought and Reform in Iran, Cambridge: Cambridge University Press, 2019.

29 Osvaldo Coggiola, A revolução iraniana, São Paulo: Unesp, 2008; Farhad Gohardani e Zahra Tizro, The Political Economy of Iran: Development, Revolution and Political Violence, Nova York: Palgrave Macmillan, 2019.

30 Sarah Ansari e Vanessa Martin (orgs.), Women, Religion and Culture in Iran, Londres: Routledge, 2002; DeSouza, Unveiling Men; Kevan Harris, A Social Revolution: Politics and the Welfare State in Iran, Oakland: University of California Press, 2017; Stephanie Cronin (org.), Anti-Veiling Campaigns in the Muslim World: Gender, Modernism and the Politics of Dress, Londres: Routledge, 2014; Sedghi, Women and Politics in Iran. 
do passado pré-islâmico e da origem ariana do povo, ${ }^{31}$ forjando uma identidade iraniana cosmopolita, mas enraizada num passado singular. ${ }^{32}$

Surgiram forças de oposição nesse contexto de forte repressão, crise econômica e reformas pró-Ocidente e anti-islâmicas das décadas de 1960 e 1970. A oposição era composta por esquerdistas islâmicos e ateus, liberais e muçulmanos tradicionalistas, comerciantes urbanos dos bazares, camponeses prejudicados pela mecanização do campo e elites descontentes com a crescente presença norte-americana. ${ }^{33}$

Na primeira metade da década de 1960, uma autoridade religiosa que vinha se opondo à ocidentalização do país, o aiatolá Khomeini, então exilado, conseguia divulgar os seus discursos contrários à monarquia por meio de fitas-cassete enviadas aos mais recônditos cantos do Irã e, assim, liderar a oposição ao regime. Enquanto isso, as ruas das principais cidades eram tomadas por protestos ao longo de toda a década de 1970, reprimidos com muita violência, culminando, entre o final de 1978 e o início de 1979, com a fuga do xá, o regresso de Khomeini ao país em fevereiro e a declaração da República Islâmica em abril do mesmo ano. ${ }^{34}$

Contratado pelo Corriere della Sera, Foucault realizou duas viagens ao Irã para contribuir em uma seção do diário com textos de opinião produzidos por intelectuais acerca dos principais acontecimentos do momento. ${ }^{35}$ Nos primeiros textos, a modernização promovida pelo xá foi

31 Reza Zia-Ebrahimi, The Emergence of Iranian Nationalism: Race and Politics of Dislocations, Nova York: Columbia University Press, 2016.

32 Ervand Abrahamian, Iran Between Two Revolutions, Princeton: Princeton University Press, 1982; Hamid Dabashi, Iran: The Rebirth of a Nation, Nova York: Palgrave Macmillam, 2016; Mohsen Milani, The Making of Iran's Islamic Revolution: From Monarchy to Islamic Republic, Boulder: Westview Press, 1994.

33 Harris, A Social Revolution.

34 Saïd Arjomand, The Turban for the Crown: the Islamic Revolution in Iran, Oxford: Oxford University Press, 1988; Coggiola, A Revolução Iraniana; Nikki Keddie, Roots of Revolution: An Interpretive History of Modern Iran, New Haven: Yale University Press, 1981.

35 A primeira, entre 16 e 24 de setembro de 1978; a segunda, de 9 a 15 de novembro de 1978. Ao todo, foram oito textos publicados no jornal italiano, três na revista semanal francesa Le Nouvel Observateur, um no diário Le Matin e, enfim, um último em outro diário, Le Monde, além de uma entrevista publicada em um livro. O conjunto 
apresentada como um “arcaísmo”. Foucault afirmou que a dinastia Pahlavi não conseguiu basear sua política no nacionalismo (pois a dominação externa sempre esteve presente) e na laicidade (pois o xiismo construiu o verdadeiro princípio da “consciência nacional”), restando-lhe, então, a modernização à moda europeia. Como crítico da modernidade, Foucault viu ali o maior problema do regime, concluindo que: “[o] arcaísmo hoje é seu projeto de modernização, suas armas de déspota, seu sistema de corrupção. O arcaísmo é o 'regime’”. ${ }^{36} \mathrm{O}$ texto ganhou uma versão persa, afixado nos muros da Universidade de Teerã para o deleite dos estudantes como um apoio do filósofo aos protestos.

Em outro texto, Foucault afirmou, após seu encontro com um aiatolá, que o clero xiita não era necessariamente uma força política, mas estaria se tornando uma, naquele momento, por catalisar os desejos das camadas populares. Concluiu que a Pérsia teria inventado o Estado e a administração; “confiou as receitas ao Islã e seus administradores serviram de quadro para o império árabe. Mas, desse mesmo Islã, ela fez derivar uma religião que não cessou, através dos séculos, de dar uma força irredutível a tudo o que, do fundo de um povo, pode se opor ao poder do Estado". ${ }^{37}$

O primeiro texto de autoria de Foucault sobre o Irã, publicado em francês, foi o mais polêmico. Nele é proposto o caminho para se relacionar política e espiritualidade como um antídoto aos excessos da modernidade. Intitulado “Com o que sonham os iranianos?”, o texto parte da análise da incapacidade do xá de desenvolver economicamente o país nos moldes de um regime liberal, moderno e ocidentalizado. A situação no Irã se resumia a uma disputa entre "o rei e o santo, o soberano com armas e o exilado

foi publicado em livro: Michel Foucault, Dits et Écrits II, Paris: Gallimard, 2001. Recentemente, foram publicadas outras duas entrevistas, uma concedida a Le Nouvel Observateur, no início de janeiro de 1979, e uma concedida ao filósofo Farès Sassine em agosto de 1979: Michel Foucault, O enigma da revolta: entrevistas inéditas sobre a revolução iraniana, São Paulo: n-1 Edições, 2019.

36 Foucault, Dits et Écrits II, p. 683.

37 Foucault, Dits et Écrits II, p. 688. 
desmunido; o déspota e, frente a ele, o homem que se levanta com as mãos vazias aclamado por um povo”, fazendo referência a Khomeini. ${ }^{38}$ Em seu exílio em Paris, o aiatolá instava os estudantes iranianos, os muçulmanos em geral e as forças armadas, em nome do Alcorão e do nacionalismo, a se opor ao xá, por meio de discursos gravados em fitas cassete e enviados aos quatro cantos do Irã.

Para Foucault, seguindo o que lhe diziam alguns membros de partidos proibidos desde a década de 1960, Khomeini era só um nome para chamar a população para a ação contra o regime autoritário. Passada a turbulência, os partidos e a vida política retomariam o processo de democratização do país. Foucault apresentou, nesse texto, uma análise feita a partir das observações em Teerã, Abadan - onde se encontram os poços e refinarias de petróleo - e Qom - a cidade onde se forma o clero xiita. Ele perguntava a estudantes, membros do clero, proletários e intelectuais - não aos políticos - com o que sonhavam. A resposta obtida, em sua grande maioria, teria sido: “um governo islâmico".

Foucault se perguntou o que isso queria dizer num país majoritariamente muçulmano, mas não árabe e não sunita, menos sensível aos interesses pan-islâmicos e pan-árabes em voga naquele momento em razão da "questão israelense". O que as pessoas pareciam entender por "governo islâmico" era algo que não teria nada a ver com um regime político no qual o clero ocuparia o papel de fato de poder político; tratava-se de uma utopia, como voltar aos primórdios do islamismo até que somente a “criatividade” do Islã agisse, independentemente das leis seculares. Essa percepção traçou o caminho até a introdução de uma dimensão espiritual na política: "fazer com que essa vida política não seja, como sempre foi, um obstáculo para a espiritualidade, mas o seu receptáculo, sua ocasião, seu fermento". 39

Nos textos seguintes, Foucault desenvolveria melhor a ideia da negação da modernidade pela espiritualidade, o que, para ele, era a marca

38 Foucault, Dits et Écrits II, p. 689.

39 Foucault, Dits et Écrits II, p. 693. 
inovadora do movimento iraniano. O autor, entretanto, começou a perceber que despontava uma tensão entre os partidos políticos e a espiritualidade a partir do momento em que Khomeini anunciou que, quando o xá fosse deposto, proporia um referendo para a adoção do governo islâmico. Apesar disso, o movimento parecia fruto de uma "vontade coletiva perfeitamente unificada” raramente vista na história recente da “ordem política”, sem que, paradoxalmente, tenha sido criada por ou feito surgir uma ideologia política única representativa do movimento ou tenha sido criada por ela. ${ }^{40}$

A "vontade coletiva perfeitamente unificada", resumida na reivindicação de derrubada do xá, significava “o fim da dependência, o desaparecimento da polícia, a redistribuição da renda do petróleo, a caça à corrupção, a reativação do Islã, um outro modo de vida, novas relações com o Ocidente, com os países árabes, com a Ásia etc.”. ${ }^{41}$ Era nesse contexto que despontava Khomeini, que não teria a intenção de se envolver na política: “não haverá um partido de Khomeini, não haverá um governo Khomeini. Khomeini é o ponto de fixação de uma vontade coletiva”. ${ }^{42}$ Afinal, era: "um movimento atravessado pelo sopro de uma religião que fala menos do além do que da transfiguração desse mundo". ${ }^{43}$ No último texto para o Corriere, publicado em 13 de fevereiro de 1979 (dois dias depois da ascensão de Khomeini ao poder), Foucault sugeriu que deveria, então, começar o ato principal da encenação, aquele em que a luta de classes, as vanguardas armadas e os partidos organizadores das massas populares, dentre outras categorias, entrariam em cena. Termina o texto com muita prudência sobre o futuro do país, já que não conseguia opinar sobre a surpreendente estratégia política dos religiosos, agora no poder.

Em março de 1979, a República Islâmica do Irã era proclamada, com Khomeini à sua frente como Líder Supremo. No dia 8, as mulheres

40 Foucault, Dits et Écrits II, p. 715.

41 Foucault, Dits et Écrits II, p. 715.

42 Foucault, Dits et Écrits II, p. 716.

43 Foucault, Dits et Écrits II, p. 716. 
iranianas comemorariam pela primeira vez o Dia Internacional das Mulheres e, para a ocasião, foi convidada para uma série de atividades em Teerã a feminista estadunidense Kate Millet, que vinha militando contra o regime do xá havia alguns anos. No dia 7 de março, Khomeini havia declarado que todas as mulheres no país deveriam, obrigatoriamente, respeitar o uso do véu e estavam proibidas as maquiagens. No dia seguinte, milhares de mulheres foram às ruas protestar contra o fato de que não teriam ajudado a revolução - trajando o véu durante as manifestações como sinal de oposição à ocidentalização imposta pelo xá - para se verem agora prisioneiras das interpretações religiosas, com força de lei, de Khomeini. ${ }^{44}$

Contra as primeiras execuções de opositores/as, os protestos continuaram nos dias que seguiram, com o apoio de feministas estrangeiras. ${ }^{45}$ Em Paris, Millet, Beauvoir e outras feministas organizaram um evento público em apoio às mulheres iranianas, durante o qual Beauvoir afirmou que “[o] novo regime será uma tirania se não levar em consideração os seus [das mulheres] desejos e não respeitar os seus [das mulheres] direitos”. ${ }^{46}$

Diante das atrocidades imputadas às milícias paramilitares, os jornalistas franceses Claudie e Jacques Broyelle lançaram, na edição de 24 de março de 1979 do diário Le Matin, um desafio a Foucault, sob o título irônico “Com o que sonham os filósofos?”, para que ele se pronunciasse sobre sua interpretação da atualidade iraniana. Dois dias depois foi publicada sua resposta, bastante curta, informando que nunca havia tomado partido em polêmicas públicas. ${ }^{47}$ Em novembro de 1978,

44 Marie-Jo Bonnet, Mon MLF, Paris: Albin Michel, 2018.

45 Janet Afary e Kevin Anderson (orgs.), Foucault and the Iranian Revolution: Gender and the Seductions of Islamism, Chicago: Chicago University Press, 2005; Jean Gueyras, "Les manifestations des femmes amènent l'ayatollah Khomeiny a nuancer sa position sur le 'voile islamique'”, Le Monde, 13 mar. 1979; Jean Gueyras, "Les formations de gauche déconseillent aux femmes la poursuite des manifestations de rue”, Le Monde, 14 mar. 1979; Kate Millet, Going to Iran, Nova York: Simon \& Schuster, 1981.

46 Beauvoir apud Bonnet, Mon MLF.

47 Foucault, Dits et Écrits II. 
Le Nouvel Observateur já havia publicado uma carta assinada com um pseudônimo feminino persa, Atoussa H., alertando para que a esquerda ocidental e Foucault em particular tomassem cuidado com a maneira como vinham exaltando a suposta "espiritualidade política” islâmica e, desse modo, menosprezando as consequências do fanatismo religioso que parecia subjazer a essa espiritualidade e obstava a liberdade das mulheres. Foucault respondeu, em poucas linhas, acusando a leitora de desconhecer as potencialidades do islamismo. Mas Foucault já vinha se mostrando preocupado com os rumos tomados pela revolução, já em fase de consolidação entre março e abril de 1979, e chegou até a publicar uma carta aberta ao primeiro-ministro, em Le Nouvel Observateur, para sugerir a vigilância do governo.

Em 11 ou 12 de maio de 1979, Foucault teve um artigo publicado na primeira página do diário Le Monde, intitulado “Inútil se insurgir?”. Ele começava o texto lembrando que, no ano anterior, os iranianos diziam que, para que o xá fosse destituído, estariam prontos a pagar com suas próprias vidas. Agora, era Khomeini que dizia que o Irã tinha que sangrar para que a revolução produzisse bons frutos. Para o filósofo, essas duas frases ecoavam de forma estranha. Ele reconheceu que não esperava que o religioso se tornasse o poder central, afirmou que o clero parecia ter, de fato, ambições políticas, contrariamente ao que havia dito em textos anteriores, e elencou alguns fatores para a explicação do que estava ocorrendo, relacionando-os ao islamismo: "a formidável esperança de reconstruir o Islã como uma grande civilização viva, e as formas de xenofobia virulentas; os desafios mundiais e as rivalidades regionais. E o problema dos imperialismos. E o assujeitamento das mulheres etc.” ${ }^{48}$

Bonnet, dentre as tantas ativistas mulheres e homossexuais/lésbicas da época, diante do texto de Foucault, demonstrou sua indignação com o fato de que um dos maiores expoentes da filosofia mundial do momento, que vivenciara o movimento revolucionário, não escreveu sequer uma

48 Foucault, Dits et Écrits II, pp. 792-793. 
linha sobre o que, em geral, vinha acontecendo contra as mulheres e as pessoas homossexuais desde a volta de Khomeini ao Irã. ${ }^{49}$

Foucault não mais se pronunciou sobre o Irã até a sua morte em $1984 .{ }^{50}$ No Irã, virou uma espécie de mártir da revolução, sendo lembrado como um filósofo apoiador da causa revolucionária, ou da "espiritualidade política” encarnada pelos três setores da sociedade com os quais esteve durante as suas viagens: o clero, os comerciantes dos bazares e o proletariado do petróleo, três importantes bases de sustentação do movimento revolucionário e do regime iraniano até a atualidade.

\section{Após Foucault}

Foucault não tinha por que não ser "um herói”, como dito pelo recepcionista do hotel em Isfahan. Os textos de Khomeini divulgados desde a década de 1960 e as leis do governo islâmico oriundo da revolução, assim como as instâncias diversas de controle social e de enquadramento biopolítico que passaram a dar forma à nação iraniana, ${ }^{51}$ colocaram a disciplina dos corpos e a ordenação da vida sexual como prioridades máximas, exatamente como a modernidade havia feito no Ocidente - e contra a qual Foucault vinha escrevendo. A Revolução, as falas de Khomeini gravadas em fitas cassete, seus textos e seus atos no exílio tinham um grande potencial de crítica à modernidade ocidental. Para os ideólogos do

49 Bonnet, Mon MLF.

50 Em mais uma entrevista, publicada recentemente, Foucault discorre sobre as críticas à "espiritualidade política”, mas nada acrescenta sobre as críticas feministas ou a perseguição a homossexuais - cf. Foucault, $O$ enigma da revolta.

51 Imam Khomeini, Governance of the Jurist (Velayat e-Faqeeh / Hokumat e- Eslami), Teerã: Institute for Compilation and Publication of Imam Khomeini's Works, s/d [1970]; Principes Politiques, Philosophiques, Sociaux et Religieux de l'Ayatollah Khomeyni [Le Livre Vert de Khomeyni], Paris: Éditions Libres-Hallier, 1979; e Islam and Revolution - The Writings and Declarations of Imam Khomeini as Translated by Hamid Algar, Londres: Routledge, 2010. 
novo regime, Foucault podia aparecer como um aliado por acreditar que a “espiritualidade política” alimentava aquele potencial.

O filósofo estava, na segunda metade da década de 1970, dando suas aulas no Collège de France sobre os temas governo, poder pastoral e biopoder, ou seja, da governamentalidade e seus dispositivos biopolíticos. $^{52}$ No Irã, ao longo das décadas de 1980 e 1990, o "renascimento da nação"53 aconteceria por iniciativa do Estado teocrático precisamente com a remontagem da governamentalidade, sobre bases diferentes daquelas vigentes durante a monarquia, através da instauração de tecnologias de poder-saber que atuariam para viabilizar a disciplinarização dos corpos, marcados por uma verdadeira obsessão pela ordenação biopolítica da vida sexual. Assim, a “espiritualidade política”, agora estatizada, estaria se servindo daquilo que tinha de mais perverso na modernidade ocidental e que Foucault vinha denunciando em seus escritos. ${ }^{54}$

Nos anos imediatamente após a revolução, o Estado teocrático foi se consolidando com o suporte de uma nova Constituição, que criava uma forma de governo peculiar baseada na aplicação da lei islâmica, a xariá, ${ }^{55}$ e a fusão do religioso com o político, tendo o Líder Religioso à frente do Estado. ${ }^{56} \mathrm{O}$ Líder, o aiatolá, concentra, de fato, o poder e, de direito, controla os meios de comunicação, as políticas culturais nacionalistas e até os movimentos sociais institucionalizados pelo próprio Estado, além de se servir da Guarda Revolucionária para fazer cumprir o modelo de governamentalidade vigente com o intuito de fundir a esfera pública e da

52 Foucault, Sécurité, Territoire, Population; Naissance de la Biopolitique.

53 Dabashi, Iran.

54 Fariba Adelkhan, Être Moderne en Iran, Paris: Karthala, 1998.

55 A xariá ou sharia, lei canônica do Islã, baseia-se no Alcorão e na tradição que compreende os atos e palavras do Profeta e deduções por analogia emitidas por teólogos-juristas - cf. Buresi, "Histoire de l'Islam”.

56 Para o modo de funcionamento do Estado e do governo no Irã, ver: Bruna Moura Bruno, "Espiritualidade política no governo de Khomeini: o sistema político do Irã após a revolução de 1979”, Dissertação (Mestrado em Sociologia Política), Universidade Federal de Santa Catarina, Florianópolis, 2014; Wilfried Buchta, Who Rules Iran? The Structure of Power in the Islamic Republic, Washington: The Washington Institute for Near East Policy; Konrad Adenauer Stiftung, 2000. 
esfera privada numa mesma e única dimensão da vida, instituindo uma nova moralidade sob os auspícios do clero e suas interpretações sagradas. ${ }^{57}$

Aproveitando-se da instabilidade no Irã, o Iraque invadiu uma área de disputa de fronteiras, resultando em uma guerra que duraria até 1988 e deixaria mais de setecentos mil mortos, financiada, do lado iraquiano, pelos Estados Unidos e pela Arábia Saudita. A guerra fortaleceu o poder dos aiatolás e o ódio ao Ocidente, encarnado pelos Estados Unidos, permitindo que a oposição fosse banida por meio do uso de violência e que toda forma de dissidência fosse enquadrada pela necessidade de se honrar os mártires da guerra. ${ }^{58}$ Com a crise econômica, começaram a surgir divergências entre os aiatolás na maneira de lidar com o principal produto de exportação do país, o petróleo: uma ala moderada "reformista” defendia parcerias com países ocidentais, enquanto a ala mais "conservadora” temia as influências estrangeiras. ${ }^{59}$ A morte de Khomeini, em 1989, e a sua substituição pelo atual líder, o aiatolá Khamenei, favoreceu uma postura mais moderada, levando ao poder entre 1989 e 2005 dois presidentes (Rafsanjani e Khatami) que empreenderam reformas econômicas importantes em busca de uma reaproximação paulatina com o Ocidente, além de pequenas concessões no que diz respeito aos aspectos biopolíticos do governo - como o direito de mulheres usarem roupas moderadamente coloridas. ${ }^{60}$

A luta antiterrorista empreendida pelos Estado Unidos e aliados após 2001, com acusações ao Irã de estar ocultando um programa nuclear para fins bélicos e de financiar o terrorismo no mundo, contribuiu para

57 Arjomand, The Turban for the Crown; Mehrzad Boroujerdi e Kourosh Rahimkhani, Postrevolutionary Iran: A Political Handbook, Syracuse: Syracuse University Press, 2018; Saeid Golkar, Captive Society: the Basij Militia and Social Control in Iran, Washington: Woodrow Wilson Center Press, 2015.

58 Pedram Khosronejad, Unburied Memories: The Politics of Bodies of Sacred Defense Martyrs in Iran, Nova York: Routledge, 2013; Ray Takieh, Guardians of the Revolution: Iran and the World in the Age of the Ayatollahs, Oxford: Oxford University Press, 2009.

59 Adelkhan, Etre Moderne en Iran.

60 Abrahamian, A History of Modern Iran; Sadeghi-Boroujerdi, Revolution and Its Discontents. 
reforçar sentimentos conservadores que desembocaram na eleição presidencial de um ex-membro da Guarda Revolucionária, Ahmadinejad. O governo radicalizou a oposição ao Ocidente e valorizou o alinhamento com a China e outros países contrários à hegemonia euro-estadunidense. ${ }^{61}$ No momento de sua contestada reeleição, milhares de iranianas/os foram às ruas protestar a favor do candidato reformista, vestidos de verde, numa série de manifestações reprimidas violentamente que ficaram conhecidas como Revolução Verde. Esse foi o início de um período, que ainda perdura, de demonstrações públicas de descontentamento em relação aos excessos do regime. ${ }^{62}$ Com os líderes da Revolução Verde presos e muitas candidaturas de reformistas banidas pelo Conselho dos Guardiães, o moderado Hassan Rouhani foi eleito presidente em 2013 e reeleito em 2017. Passaram a se desenvolver, de forma mais incisiva, o que aqui será chamado de “paisagens heterotópicas”, essas formas de reação e resistência que materializam a reivindicação de mudanças permanentes.

Enfim, entre "reformistas” e “conservadores”, parece ter-se criado ali, nos últimos quarenta anos, uma sociedade multidimensional única: situado acima de tudo, o Estado e sua utopia constitucional baseada na xariá e nas pregações; acima de todos, a distopia gerada pela tentacular Guarda Revolucionária e a truculenta Basij, sua ramificação paramilitar; e enfim, entre a utopia e a distopia, as heterotopias criativas.

A utopia funciona com imposições severas: mulheres devem trajar em público um véu sobre a cabeça (hijab) e uma roupa que lhes cubra todo o tronco até abaixo das nádegas (manteau), além dos braços, as pernas e os pés, e uma calça ou saia longa, de preferência com um longo pano preto por cima de tudo (abaya); não podem cantar nem dançar em público; não devem sair às ruas desacompanhadas de homens de sua própria família e, quando acompanhadas de um homem, devem justificar a sua presença;

61 Garver, John W., China \& Iran: ancient partners in a post-imperial world, Seattle: University of Washington Press, 2006.

62 Hamid Dabashi, The Green Movement in Iran, New Brunswick: Transaction Publishers, 2011. 
há lugares separados nos restaurantes para homens desacompanhados não se misturarem com as famílias e mulheres; as práticas sexuais entre pessoas do mesmo sexo ou gênero são passíveis de pena capital; diversos crimes são punidos com chicotadas; salões de beleza femininos são regulamentados, geralmente proibidos, assim como o uso de maquiagem; embora não seja obrigatório, homens devem portar barba e bigode e não devem usar brincos e piercings, nem tatuagens à mostra, nem bermudas ou shorts em público etc. ${ }^{63}$ A distopia, por exemplo, é a realidade das mulheres conduzidas a um posto policial para justificar as cores e os decotes de sua roupa; ou de homens afeminados sendo dirigidos a uma clínica para a realização de exames médicos que os forcem à cirurgia de redesignação sexual etc. ${ }^{64}$

\section{Paisagens heterotópicas}

As múltiplas performances para sobreviver à distopia e contrariar a utopia parecem caracterizar a realidade cotidiana de algumas pessoas no Irã há quarenta anos, conformando verdadeiras paisagens heterotópicas que desafiam o Estado e o projeto nacional islâmico. Foucault não estava errado ao apontar a "espiritualidade política” como a marca do movimento revolucionário, mas não podia imaginar o que dela seria feito. ${ }^{65}$ Desde a revolução, deseja-se instituir uma forma islâmica de religiosidade, tal qual pensada por Khomeini e seus apoiadores, como o ponto de fixação daquilo que Foucault definiu como a "vontade coletiva perfeitamente unificada” que fizesse da vida política um "receptáculo da

63 Roksana Bahramitash e Eric Hooglund (orgs.), Gender in Contemporary Iran: Pushing the Boundaries, Londres: Routledge, 2011.

64 Afsaneh Najmabadi, Professing Selves: Transsexuality and Same-Sex Desire in Contemporary Iran, Durham: Duke University Press, 2014.

65 Behrooz Ghamari-Tabrizi, Foucault in Iran: Islamic Revolution After the Enlightenment, Minneapolis: University of Minnesota Press, 2016. 
espiritualidade”66 - inclusive servindo-se da Guarda Revolucionária e suas ramificações para fazer valer, de forma distópica, a utopia moral da "transfiguração desse mundo" assim constitucionalmente assentada. ${ }^{67} \mathrm{O}$ que se observa, porém, na vida cotidiana das pessoas, parece ser a transfiguração dessa espiritualidade política em formas múltiplas de heterotopias prenunciadoras de disrupturas permanentes.

O projeto nacional investiria em metáforas de utopia (tais como monumentos aos mártires das guerras por toda parte, propagandas oficiais anti-Ocidente nos muros e nas televisões, coleções museológicas de supervalorização do passado islâmico etc.), enquanto se desenvolvem meta-projetos nacionais alternativos baseados em metonímias heterotópicas (tais como o véu colocado de modo a deixar à mostra a metade da cabeça, o uso de maquiagem por rapazes afeminados, o evitamento da barba, a ingestão de coquetéis sem álcool em cafés que mais parecem bares etc.). Passarei, a partir daqui, a tratar dessas heterotopias como paisagens que materializam pouco a pouco as mudanças em andamento ou a proposta de outra “espiritualidade política”?

“O corpo humano é o ator principal de todas as utopias”, ${ }^{68}$ - daí as investidas governamentais para a produção de um regime de verdade que naturalize utopicamente o dimorfismo sexual, o binarismo de gênero e a heteronormatividade como efeitos incontestes de uma forma de biopoder imposta pelo clero. As heterotopias, para Foucault, seriam "lugares que se opõem a todos os outros, destinados, de certo modo, a apagá-los, neutralizá-los ou purificá-los”, ${ }^{69}$ ou seja, contraespaços “de contestação dos outros espaços”. ${ }^{70}$

Estendendo o sentido do conceito, proponho considerar as heterotopias, não somente como lugares e espaços - topos - como o fez

66 Foucault, Dits et Écrits II, p. 693.

67 Foucault, Dits et Écrits II, p. 716; Garver, China \& Iran.

68 Foucault, $O$ Enigma da Revolta, p. 14.

69 Foucault, O Enigma da Revolta, p. 20.

70 Foucault, O Enigma da Revolta, p. 28. 
Kjaran para analisar as experiências da diversidade sexual e de gênero no Irã, ${ }^{71}$ mas também como ações, símbolos, pensamentos e sensações que compõem paisagens sociais. As paisagens heterotópicas são, desse modo, "conjunto[s] variado[s] de elementos relacionados"72 que remetem à formação de biografias individuais por meio da memória e das experiências cotidianas, que são, então, compartilhados socialmente ${ }^{73}$ para fazer frente às distopias ou utopias vigentes e seus sistemas de dominação. ${ }^{74}$

\section{Sem véu e sem barba nos espaços de sociabilidade}

A primeira coisa que me chamou a atenção, enquanto o avião ainda taxiava no pátio do aeroporto de Isfahan, foi a movimentação das passageiras mulheres, inclusive as turistas, apressando-se para colocar o hijab e reduzir a maquiagem facial. Como visto em seções anteriores, a situação das mulheres mudou bastante entre os séculos XIX e XX; no passado, o uso do hijab chegou a ser proibido durante grande parte do século, enquanto foram conquistados os direitos ao voto, à educação mista laica, ao divórcio por iniciativa da mulher, dentre tantos outros - principalmente acionados por mulheres urbanas. Grande parte desses direitos foi, porém, reconfigurado após a Revolução; alguns deles limitados para se adequar à doutrina natalista instaurada por Khomeini com o objetivo de incrementar

71 Jón Kjaran, Gay Life Stories: Same-Sex Desires in Post-Revolutionary Iran, Cham: Palgrave Macmillan, 2019.

72 Tim Ingold, “The Temporality of the Landscape” in The Perception of the Environment (Londres: Routledge, 2000), pp. 189-208.

73 Chris Tilley, "Space, Place, Landscape and Perception: Phenomenological Perspectives" in Chris Tilley, A Phenomenology of Landscape: Places, Paths and Monuments (Oxford: Berg, 1994), pp. 7-34.

$74 \mathrm{O}$ sentido que o conceito de heterotopia adquire aqui, que vai além daquele proposto por Foucault, tem um caráter de alternativa emancipadora em relação às formas de opressão vigentes e se aproxiama, assim, do sentido proposto por Santos e Mandujano - Boaventura de Sousa Santos, A Crítica da Razão Indolente, São Paulo: Cortez, 2002; Miguel Mandujano, "Frontera al Norte, Utopía al Sur: paradigma dominante y alternativa cosmopolita”, Cuadernos Americanos, v. 140, n. 2 (2012), pp. 147-165. 
a população face aos vizinhos inimigos. Muito se escreveu, geralmente por pesquisadoras iranianas radicadas no exterior, sobre a vida das mulheres no Irã sob o governo islâmico ${ }^{75}$ - em particular sobre as limitações dos direitos das mulheres, as suas reações e os movimentos sociais permitidos desde a revolução. ${ }^{76}$ Nos noticiários ocidentais e nos sites de compartilhamento de vídeos, abundam as reportagens e documentários sobre as limitações dos direitos das mulheres no país, pouco se abordando as formas criativas e originais de se contrapor às tantas restrições, tema desta seção.

Não demorou muito, ainda na primeira caminhada em Isfahan, para me deparar com os sorrisos de grupos de jovens mulheres vestidas com manteaux justos e coloridos e véus floridos, maquiagem delineando olhos e bocas, unhas esmaltadas e grande parte dos cachos capilares visíveis; poucos homens jovens usavam barba, sempre trajando calças compridas e camisas justas, tênis e casacos de marcas ocidentais, cabelos penteados com gel e bastante perfumados. ${ }^{77}$ Escolhi um dos inúmeros cafés escondidos em um pátio florido do bazar para experimentar a "cultura de cafés” do Irã. Como os bares e as bebidas alcoólicas são proibidos, inclusive nos hotéis, restam os cafés como importantes espaços de sociabilidade. Nesse café tocava música estrangeira, dois rapazes e uma moça conversavam numa mesa, um aparente casal de rapazes gays, de mãos dadas e se

75 Bahramitash e Hooglund (orgs.), Gender in Contemporary Iran; Sedghi, Women and Politics in Iran; Hammed Shahidian, Women in Iran: Gender politics in the Islamic Republic, Westport; Londres: Greenwood Press, 2002; Sanam Vakil, Women and Politics in the Islamic Republic of Iran: Action and Reaction, Nova York: Continuum, 2011.

76 Ansari e Martin, Women, Religion and Culture in Iran; Azadeh Fatehrad, Women's Lives in Post-Revolutionary Iran, Londres: HammerOn Press, 2018; Ziba Mir-Hossein, Islam and Gender: The Religious Debate in Contemporary Iran, Princeton: Princeton University Press, 1999; Arzoo Osanloo, The Politics of Women's Rights in Iran, Princeton: Princeton University Press, 2009; Tara Povey e Elahen Rostami-Povey (orgs.), Women, Power and Politics in 21st Century Iran, Londres: Routledge, 2012.

77 Sobre véus e barba no mundo islâmico, cf. Allamah Murtada al-Baghadi, The Islamic Perspective of the Beard, Birmingham: Al-Mahdi Institute of Islamic Studies, 1999; Theodore Gabriel e Rabiba Hannan, Islam and the Veil: Theoretical and Regional Contexts, Nova York: Continuum International Publishing Group, 2011; Najmabadi, Women With Mustaches and Men Without Beards. 
acariciando a cabeça, conversava em outra mesa e o casal de atendentes (ela com o hijab caído nas costas e um manteau justo), vestidos de calça jeans e camisa, falavam inglês fluentemente. A decoração era de temática religiosa, com representações cristãs, hinduístas e zoroastristas. O balcão parecia o de qualquer bar alternativo brasileiro, com bebidas expostas para a preparação de coquetéis sem álcool, além de cafés e chás. Chamou-me atenção a foto do aiatolá Khamenei num altar ao lado do balcão, junto com estátuas de budas e deuses indianos. Todos os estabelecimentos públicos devem ter a foto do aiatolá. Mas, para driblar de modo heterotópico essa exigência, percebi que alguns, principalmente os cafés, "escondiam” a imagem em meio a outros tantos objetos. Num determinado momento, percebi que a atendente puxou o véu para a cabeça, ainda que pela metade, e baixou o som, até substituir por canções iranianas.

Uma grande avenida recém-pedestrianizada, que contorna um lado do centro histórico (no subsolo da qual se encontra uma novíssima linha de metrô), é ocupada à tarde por cafés ambulantes e milhares de pessoas com vestimentas bem “descoladas”; algumas mulheres com o véu caído para trás se aglomeram ali. Numa das extremidades dessa avenida, encontra-se uma das pontes que atravessam o Rio Zayandeh em direção ao bairro armênio. Quatro dessas pontes históricas interligadas por jardins configuram-se como verdadeiros pontos de encontro de uma massa jovem que, ao longo do dia, aproveita as arcadas para flertar - as da Ponte Khajoo, devido à acústica, atrai homens e mulheres que ousam cantar e dançar em público, sempre muito atentos à polícia moral.

Até mesmo dentro de espaços religiosos pude observar cenas heterotópicas: numa das mais frequentadas mesquitas de Isfahan, no centro da sala principal, algumas pessoas entoam canções. Um grupo de moças e um rapaz cantaram nesse ponto por poucos minutos e as pessoas pararam para ouvi-las, incentivando-as. As moças vieram conversar comigo em inglês, queriam saber de onde eu era, se estava gostando da cidade; eu perguntei se podiam cantar ali, elas riram e responderam que não, mas que tinham que cantar rapidamente; uma delas tinha um bottom com as 
cores do arco-íris, símbolo internacional das causas LGBTQIA+ ${ }^{78}-\mathrm{eu}$ disse que achava bonito e perguntei o que ela achava; ela riu e disse que eu sabia o que era, que ela gostava da diversidade; perguntei se, no Irã, essa diversidade era respeitada e ela respondeu que, nas ruas, não; o rapaz que estava com elas sorriu e piscou o olho. Em outra mesquita, moças baixavam o véu para tirar fotografias selfie.

Alguns dias depois, em Teerã, tive algumas outras experiências curiosas das heterotopias iranianas. A capital se estende das montanhas, ao norte, às áreas planas desérticas, ao sul. A zona norte concentra a população mais abastada, com edifícios modernos, shopping centers, restaurantes e cafés ocidentalizados; a zona ao sul do gigantesco bazar está em crescente expansão populacional, com milhares de pequenas casas distribuídas em um emaranhado de vielas, muitas mesquitas e áreas cultivadas em que vive a população empobrecida e geralmente conservadora, mais vigiada. Ao visitar um centro cultural nas proximidades da antiga Embaixada dos Estados Unidos, deparei-me com uma apresentação teatral, parte do Festival Internacional de Teatro de Teerã. Um rapaz se aproximou e me entregou, discretamente, um convite escrito em persa e em inglês para um vernissage em uma galeria de arte. Ele me disse em inglês que estrangeiros eram bem-vindos, “quietly” (discretamente); rapidamente, entendi que se tratava de uma galeria clandestina, como muitas na cidade, mantidas por artistas que pretendem assim evitar a censura.

Não muito distante dali, numa das principais avenidas de Teerã, que liga as zonas sul e norte, encontra-se um café frequentado por intelectuais e estudantes locais e faz as vezes de biblioteca/livraria. O café tem uma janela que vai do chão ao teto dando para a calçada da avenida, o que torna o ambiente visível da rua. Novamente aqui, mais se parece com um bar. Algumas mesas estavam ocupadas por homens e mulheres discutindo, em persa e em línguas estrangeiras, aparentemente, temas relacionados aos livros pegos nas estantes. Outras mesas contavam com jovens casais,

78 Lésbicas, gays, bissexuais, transexuais/transgêneres, queer, intersexuais, assexuais e afins. 
mulheres praticamente sem o véu. Nenhum homem tinha barba, à exceção de um dos atendentes. Em um dos sofás, duas mulheres atraíram a minha atenção: uma delas, sem o véu, sem maquiagem, cabelos bem curtos, vestindo uma calça jeans e uma camisa; a outra, também sem o véu, usava uma saia e uma blusa; de vez em quando saíam para fumar (embora mulheres não devam fumar em público), numa dessas vezes, sem o véu. Puxei assunto com elas, perguntando sobre o endereço do vernissage constante do convite que eu havia recebido. Era só um pretexto. Muito simpáticas, elas disseram que conheciam dois artistas que iam expor nessa galeria. Na conversa, falamos da situação das mulheres e perguntei sobre experiências da diversidade sexual. Elas revelaram que eram namoradas e me perguntaram se eu era gay. Falamos muito das dificuldades de ser mulher e lésbica no Irã, mas também das "vantagens”, segundo elas, como o fato de não ser tão molestada pelos homens, em razão do controle estrito. Achei curioso, pois elas veem o controle como uma forma de proteção, mas afirmaram que “a” liberdade se vive no âmbito doméstico. São estudantes de comunicação, mantêm blogs proibidos e seus pais sabem de suas escolhas; uma delas é filha de professores da área das humanidades; a outra, filha de um engenheiro e uma jornalista; ambas de família de classe média alta, moradoras da zona norte.

Elas propuseram-me um passeio por alguns pontos da zona norte da cidade. De metrô, fomos ao bairro de Tajrish, onde poucas mulheres cobrem toda a cabeça com o véu, as roupas usadas são de grifes ocidentais, alguns homens deixam entrever suas tatuagens nos braços e raramente são barbados. O metrô de Teerã tem vagões reservados às mulheres durante todo o dia, embora tenhamos percebido que as mais jovens (trajando roupas mais ocidentalizadas) geralmente usam os vagões mistos. Em Tajrish, diversos shopping centers e lojas de fast-food locais (que imitam um estilo ocidental) contrastam com pequenas mesquitas e um bazar. De lá, fomos ver o pôr do sol num dos pontos mais frequentados pela juventude da cidade: a Ponte Tabiat, que se ergue sobre uma via expressa, e o adjacente Parque Teleghani. Eram notáveis casais de rapazes com 
moças, mas também casais de moças, algumas delas abraçadas, sempre atentas à polícia moral. Disseram-me que a polícia não faz tantos controles como antes, principalmente nessa área da cidade. Os controles aconteceriam com mais frequência nos bairros onde reside a massa populacional que apoia (ou é obrigada a apoiar?) a situação político-religiosa, como confirmado por alguns pesquisadores. ${ }^{79}$

Elas também me disseram que a situação das mulheres tinha mudado com o incremento do acesso à educação e a postos de trabalho diversificados, além do atendimento a reivindicações de direitos relacionados ao casamento e ao divórcio, o que representa avanços oriundos, segundo elas, sobretudo da Revolução Verde, também apontado por diversas autoras como Kian-Thiébaut, Ladier-Fouladi e Sedghi. ${ }^{80}$ Elas, além disso, demonstravam o tempo todo o desejo de ver o país "se abrir”. Não veem problema na inserção do país na modernidade ocidental, contrariamente ao ódio e ao ressentimento pregados por parte dos políticos e do clero a tudo o que representa o Ocidente, mas acham que as mudanças têm que acontecer com cuidado para que os avanços não se percam - o que vem sendo tratado como uma espécie de “cultura da ambivalência” por alguns estudiosos. ${ }^{81}$

Ao deixá-las, voltei ao mundo das mulheres de abaya preta e dos homens barbados no metrô. A mesma impressão dos efeitos contrastantes

79 Janet Afary, Sexual Politics in Modern Iran, Cambridge: Cambridge University Press, 2009; Kjaran, Gay Life Stories.

80 Azadeh Kian-Thiébaut, "From Motherhood to Equal Rights Advocates: the Weakening of Patriarcal Order" in Homa Katouzian e H. Shahidi (orgs.), Iran in the 21st Century: Politics, Economics and Conflict (Londres: Routledge, 2008), pp. 86-106; Marie Ladier-Fouladi, "Sociodemographic Changes in the Family and their Impact on the Sociopolitical Behavior of the Youth in Postrevolutionary Iran" in N. Nabavi (org.), Iran: from Theocracy to the Green Movement (Nova York: Palgrave Macmillan, 2012), pp. 137-166 बoj; Sedghi, Women and Politics in Iran.

81 Bahramitash e Hooglund (orgs.), Gender in Contemporary Iran; Sina Mansouri-Zeyni e Sepideh Sami, "The History of Ressentiment in Iran and the Emerging Ressentiment-less Mindset”, Iranian Studies, v. 47, n. 1 (2014), pp. 49-64 שo. O ódio ao Ocidente e as práticas correlatas para materializá-lo institucionalmente são discutidas na literatura sob o título de “westoxification” ou “ocidentoxicação”, que acaba criando, a meu ver, uma espécie de orientalismo às avessas (cf. DeSouza, Unveiling Men). 
das heterotopias e distopias tive em Isfahan no dia 11 de fevereiro, quando se comemoravam os quarenta anos da Revolução. Naquele dia, acordei com o barulho de pessoas marchando e repetindo slogans entoados do alto de carros de som. A multidão era enorme, composta por homens de roupas pretas ou cinzas que faziam gestos com o braço direito, batendo fortemente no peito, e mulheres todas de abaya preta; muitos deles carregando imagens dos aiatolás e cartazes com dizeres em persa e em inglês, como "Down With USA”, "Down With Israel”, "Down With England” trazendo os símbolos de associações islâmicas ligadas a ramificações da Guarda Revolucionária. Acompanhei alguns grupos até a praça principal, onde um palco havia sido armado, compartilhado, naquele momento, por membros do clero e, provavelmente, políticos, além de uma orquestra de jovens rapazes. De vez em quando, gritos contra alguns países eram entoados - Estados Unidos, Israel, Inglaterra, Arábia Saudita, Paquistão e Afeganistão. Toda a praça estava cercada, do alto dos prédios históricos, por atiradores de elite. Eu e meu companheiro éramos os únicos estrangeiros e não demoramos muito para perceber que as pessoas nos olhavam com ar de desconfiança, embora sempre sorrindo. Nas ruas do entorno, muitos grupos de estudantes arvoravam bandeirolas nas cores do país e pousavam para fotos perto de monumentos aos mártires da Revolução e da Guerra. Por fotografar, fui repreendido por um grupo de jovens armados vestidos com uniformes, provavelmente membros da Basij. Nenhuma mulher vestia roupas coloridas, nem deixava entrever parte dos cabelos. Percebi que, em todos os canais de televisão daquele dia, só passavam imagens das câmeras instaladas em pontos das principais cidades com multidões vestidas de preto tomando as ruas para as comemorações.

Esses pareciam ser os espaços públicos de sociabilidade aparentemente mais frequentados no Irã e, também, aqueles em que as heterotopias pareciam se visibilizar com mais facilidade para estrangeiros: as praças e parques com os famosos “jardins persas” do período pré-islâmico que encantaram os árabes; as mesquitas ricamente ornamentadas da 
era islâmica; e enfim, os cafés que se parecem com bares ocidentais o passado remoto, o presente persistente e o desejo para o futuro?

\section{Demografia, família e "casamento branco"}

Embora Khomeini tenha adotado uma política natalista para fazer frente ao despovoamento do período pré-revolucionário imediato e às perdas da guerra contra o Iraque, o controle da natalidade que marca as décadas de 1990 em diante pode ser visto como uma reação - heterotópica - por parte de famílias menos conservadoras às leis dos aiatolás, que tinham por objetivo embaraçar as fronteiras entre o domínio público (sob controle do Estado religioso) e a vida privada (ainda sob o controle das famílias), como afirmam Haghighat-Sordellini e Ladier-Fouladi. ${ }^{82}$ Essas transformações demográficas ocorreram inclusive no meio rural, com consequências nos modos de vida das mulheres. ${ }^{83}$

Os movimentos sociais de mulheres, ainda que muito limitados pelo Estado (quando não diretamente ligados a ele), tiveram um papel fundamental na negociação de direitos e no reforço de paisagens heterotópicas. Foi assim que, apesar de todas as interpretações religiosas restritivas às liberdades das mulheres no primeiro momento pós-revolucionário, conseguiram-se manter alguns direitos conquistados ao longo do século XX e até mesmo, de forma heterotópica, rever algumas interpretações ou flexibilizar a aplicação de algumas novas restrições, inclusive nas áreas rurais. ${ }^{84}$ Isso se deu não somente no âmbito da vida doméstica e familiar,

82 Elhum Haghighat-Sordellini, “Iran Within a Regional Context: Socio-Demographic Transformations and Effects on Women's Status” in Bahramitash e Hooglund (orgs.), Gender in Contemporary Iran, pp. 162-189; Ladier-Fouladi, "Sociodemographic Changes”.

83 Fatemeh Moghadam, "Economics: Agricultural Labor” in Suad Joseph (org.), Encyclopedia of Women \& Islamic Cultures (Leiden: Brill, 2007), v. 4, pp. 127-128.

84 Farhad Khosrokhavar, "Le Mouvement des Femmes en Iran”, Cahiers de Genre, v. 2, n. 33 (2002), pp. 137-154 ब여; Ziba Mir-Hosssein, "Islam, Women and Civil 
mas também no acesso à educação e ao trabalho. Apesar da segregação jurídico-religiosamente definida por gênero, hoje em dia as mulheres são tão ou mais escolarizadas do que os homens em grande parte das regiões do país, principalmente nas cidades, ${ }^{85}$ e têm acesso a praticamente todas as profissões ${ }^{86}$ - embora os cargos de chefia ainda sejam majoritariamente masculinos e algumas profissões sejam proibidas às mulheres, assim como há fortes limitações da representação feminina na política. ${ }^{87}$ A presença e o sucesso das mulheres nesses âmbitos não são vistos como benefícios outorgados pelo Estado, mas como o fruto das tensões inerentes a uma resistência bastante organizada. ${ }^{88}$

No entanto, no âmbito da vida doméstica, as prerrogativas masculinas previstas por lei acabaram reforçando, ao longo dos últimos quarenta anos, práticas de violência física e simbólica, ainda corriqueiras em grande parte das famílias, ${ }^{89}$ assim como a divisão do trabalho desfavorável às mulheres, a necessidade da maternidade para a plenitude do casamento, a obrigatoriedade da autorização do marido ou do pai para algumas atividades públicas, além de punições brutais e banimentos vergonhosos caso ocorra desrespeito às prerrogativas. ${ }^{90}$ As jovens gerações, acusadas de ocidentalizadas demais, parecem reagir de pelo menos três maneiras contrárias à naturalização dessas prerrogativas e, assim, criar esferas heterotópicas: estimulando uma vida doméstica que impeça a intromissão das forças do controle social religioso e diminua a sua confusão com o

Rights: The religious debate in the Iran of the 1990s” in Ansari e Martin (orgs.), Women, Religion and Culture in Iran, pp. 165-184; Sedghi, Women and Politics in Iran.

85 Khadijeh Aryan, “The Boom in Women's Education” in Povey e Rostami-Povey (orgs.), Women, Power and Politics, pp. 35-52.

86 Zahra Nejadbaran, "Women and Employment” in Povey e Rostami-Povey (orgs.), Women, Power and Politics, pp. 73-90.

87 Jamileh Kadivar, "Women and Executive Power" in Povey e Rostami-Povey (orgs.), Women, Power and Politics, pp. 121-136.

88 Sedghi, Women and Politics in Iran.

89 Nadia Aghtaie, “Iranian Women's Perspectives on Violence Against Women in Iran and the UK”, Iranian Studies, v. 49, n. 4 (2015), pp. 593-611 dol.

90 Vida Nassehi-Behman, “Domestic Violence. Iran and Afghanistan” in Joseph (org.), Encyclopedia of Women \& Islamic Cultures, v. 2, pp. 117-118. 
domínio público estatal; ${ }^{91}$ valorizando a igualdade de gênero no âmbito do casal:;2 se servindo das brechas nas leis e na história do islamismo para driblar as interpretações rígidas do clero, como através dos casamentos temporários previstos em lei que permitem que um casal se junte por algumas horas ou dias, somente para manter uma relação sexual. ${ }^{93}$

Na viagem de Isfahan para Shiraz, conheci Said, ${ }^{94}$ um jovem de 26 anos que abandonou a carreira de engenheiro civil para se dedicar ao turismo. Coincidentemente, a sua companheira, Fatemeh, também de 26 anos, era a recepcionista do hotel onde eu me hospedaria em Shiraz. Ele estava terminando uma segunda graduação na área de turismo, com ênfase em inglês, enquanto a sua companheira terminava uma graduação em hotelaria, com ênfase em francês. Eles haviam se casado fazia poucas semanas. Depois, ao longo da conversa, entendi que se tratava de um "casamento temporário", ainda não moravam juntos: eles tinham se conhecido na universidade, começaram a sair às escondidas e, depois de dois anos, resolveram conhecer as respectivas famílias e oficializar a relação em cartório. Quando perguntei se ele e sua companheira eram muçulmanos, ele riu e respondeu que na carteira de identidade é informado que sim, que a religião consta de todos os documentos e é informada até mesmo quando se faz o seguro de um carro! Mas, mesmo que todos se digam muçulmanos (já que essa é a religião oficial do Estado), fez questão de frisar que raramente vão às mesquitas e que os discursos não condizem com as práticas, pois mais da metade da população nasceu após a Revolução e não se vê nos ideais pregados pelos aiatolás. Em Shiraz, conheci Fatemeh e, juntos, fomos tomar um sorvete típico da cidade. Ela falava pouco, mas disse que as famílias tradicionais iranianas, como

91 Golkar, Captive Society.

92 DeSouza, Unveiling Men; Ladier-Fouladi, “Sociodemographic Changes”.

93 Floor, A Social History of Sexual Relations in Iran; Xeque Hamid Waqar, Temporary Marriage, Morrisville: Lulu.com, 2015.

94 Uso nomes fictícios para preservar o anonimato dos/as interlocutores. 
a sua, estavam mudando em razão dos modos de vidas dos mais jovens principalmente estudantes universitários.

Já em Yazd, a cidade mais zoroastrista do Irã, conheci Mohammad, um outro jovem de 26 anos, que se propôs a me levar para conhecer alguns lugarejos da região. Ele é natural de Kerman, mas se mudou com toda a família para Yazd quando uma de suas irmãs foi admitida na universidade e só poderia se inscrever se morasse com algum homem da família. Mohammad morava com os pais, uma irmã e um irmão, já que uma irmã se casou. Contou que preferia morar perto da mãe, pois ela se ocupava de todos os afazeres domésticos e nada lhe faltava. Perguntei se isso não lhe incomodava, ele disse que as pessoas mais velhas no Irã acreditavam que esse era o lugar natural da mulher na família e que sua mãe não conseguiria viver de outro modo. Ele pensava, no entanto, que as mulheres mais novas não aceitavam mais essa modalidade de domesticidade. Perguntei por que ele não era casado e respondeu que ainda não tinha dinheiro suficiente para seduzir o pai de uma pretendente. Ele cursou economia na universidade e, até 2018, trabalhava numa empresa de comércio internacional que lhe proporcionava viagens ao exterior. Mas, depois do serviço militar, com o novo embargo estadunidense e a crise econômica, muitas empresas internacionais foram obrigadas e encerrar suas atividades no país e ele passou a prestar serviços avulsos para empresas iranianas, sonhando com a possibilidade de ir morar no exterior.

Muito vaidoso, perguntei a Mohammad se era fácil sair com moças e ter relações afetivo-sexuais. Sem nenhum pudor, afirmou que as noites eram bastante "agitadas" e que se relacionava com muitas mulheres. Ele explicou que havia festas privadas, durante as quais as pessoas se sentem à vontade e "fazem as mesmas coisas que na Europa ou no Brasil": distribuíam-se bebidas alcoólicas, geralmente de fabricação artesanal, e relações sexuais fortuitas aconteciam. Said também havia falado algo semelhante quando lhe perguntei sobre o famoso vinho shiraz, dizendo que muita gente fabricava em casa e comercializava de forma clandestina. Mohammad disse que ingeria bebida alcoólica pelo menos quatro vezes 
por semana, geralmente vinho, mais barato que cerveja - muitas vezes, de baixa qualidade. Perguntei sobre as relações entre pessoas do mesmo sexo/ gênero e ele ficou um pouco constrangido. Disse que seu irmão já tinha lhe falado “disso” e feito “isso”, assim como algumas amigas, e que conhecia homens que moravam juntos: “as coisas estão mudando, já tem homens e mulheres morando juntos sem se casarem, chamado "casamento branco", por que não haveria homens também?”. O que seus pais achariam disso? - perguntei. Mohammad respondeu, assim como Said, que a maioria da população era jovem, “open-minded” por causa da internet que lhes dava acesso ao mundo, e que o futuro lhes pertencia, não era preciso respaldo dos pais ou do clero.

\section{Cultura, VPN e flash mob}

Ao visitar o sítio arqueológico de Pasárgada, onde se encontra o túmulo de Ciro, o Grande, situado a alguns quilômetros de Shiraz, conheci por acaso uma brasileira, Flávia, catarinense moradora de São Paulo. Ela estava acompanhada da família que a acolheu como hóspede (por meio de espécie de couchsurfing), ${ }^{95}$ e me apresentou a todos os membros (um casal, a mãe do marido e um filho).

Mehdi, o marido, um professor de literatura, assim como sua esposa Yasamin, falando inglês fluentemente, fez questão de me contar não só a história do local, mas também as suas perspectivas sobre a atualidade iraniana. O professor enalteceu os Impérios Aquemênida e Sassânida, informando que se tratara da primeira vez na história da humanidade em que a diversidade cultural tinha sido respeitada, que homens e mulheres tinham direitos iguais e eram tratados com respeito, que os povos conquistados tinham os mesmos direitos dos persas e não havia escravização, que

95 Pelo Couchsurfing $\boldsymbol{C}$, é possível se hospedar gratuitamente em casas de famílias em diversos países. O Irã não permite o uso desse site, mas, de forma heterotópica, famílias iranianas conseguiram desenvolver esse modelo através de outros sites. 
as práticas sexuais entre pessoas do mesmo sexo ou gênero não eram banidas, que se vivia numa verdadeira democracia... fiquei surpreso, pois ele citava fontes e autores para corroborar as informações. Desabafou: "O Irã estava muito melhor, deveríamos ler mais a nossa história passada, e não só essa associada ao islamismo”. Chegou até a dizer que a islamização tinha sido a razão para a precarização das relações sociais, principalmente após a Revolução. Perguntei se eles falavam disso em sala de aula e responderam que a literatura iraniana demonstrava isso "por si só” e que se falava disso amplamente em qualquer disciplina na escola onde trabalhavam, apesar do medo da polícia moral.

Perguntei-lhe se as pessoas estavam contentes ou se queriam mudanças. Ele respondeu que houve a tentativa de mudança pela via das eleições, em 2009, mas não foi suficiente. Mehdi afirmou que as pessoas perceberam que a mudança não viria de uma só vez, por meio de uma revolução, mas pouco a pouco, sobretudo pela via da comunicação. Como consequência da Revolução Verde, as pessoas pediram acesso livre à internet de qualidade e agora conseguiam se comunicar com o mundo, apesar de, muitas vezes, terem que driblar as interdições de forma heterotópica. Para ter acesso a sites proibidos, como Facebook, Twitter e outros estrangeiros de informação, usam-se, por exemplo, aplicativos de VPN. ${ }^{96}$

Por meio da internet, dos celulares e dos meios de comunicação alternativos, segundo Mehdi e confirmado em quase todas as conversas que tive no Irã, as pessoas se informam para além dos jornais oficiais, assistem a canais de televisão estrangeiros com o uso clandestino de antenas parabólicas, compram e vendem produtos ilegais (como bebidas alcoólicas) e anunciam eventos proibidos (festas, tertúlias, apresentações teatrais, projeções de filmes etc.), baixam livros e artigos censurados (muitas vezes valorizando o passado pré-islâmico), fazem amizade por afinidade através de aplicativos de encontros, divulgam para o mundo imagens sobre situações delicadas (como durante a repressão às manifestações de

96 Virtual Private Network, ou rede virtual privada, é um instrumento usado para ter acesso a sites que são protegidos. 
2009 em diante) e, enfim, questionam os dispositivos de poder estatais, criando aquilo que alguns pesquisadores chamam de webloguistão. ${ }^{97}$ Na esfera heterotópica assim estabelecida, parece ser possível construir uma ideia de nação que conecta o glorioso passado persa, a "espiritualidade política” islâmica e a modernidade ocidental, sem paradoxo ou contradição. ${ }^{98}$ Esse uso das novas mídias estaria impactando diretamente uma das principais marcas do regime - o controle dos corpos, do gênero e da sexualidade - ao questionar a segregação por gênero, os rígidos padrões performativos de gênero e a naturalização da heterossexualidade compulsória. Como notado por alguns pesquisadores, principalmente o caráter libertário dessas mídias para mulheres, pessoas homossexuais e sujeitos que vivem em áreas rurais. ${ }^{99}$

Em 2014, um grupo de jovens iranianos postou nas redes sociais um clipe que haviam gravado ao som de Happy, do cantor estadunidense Pharrel Williams. No vídeo, rapazes e moças vestidos com roupas coloridas ocidentais, todas elas sem véu, dançavam alegremente tocando-se os corpos. ${ }^{100}$ Gravado com um celular, o vídeo obteve milhões de visualizações, levando o grupo à prisão: homens e mulheres não aparentados não podem dançar juntos, ainda mais com roupas inadequadas. Logo após o fato, surgiram pelo mundo reações contrárias à prisão dos jovens. Outros vídeos, de vez em quando, aparecem nas redes sociais mostrando mulheres dançando em público como forma de protesto. Fatemeh contou que, uma vez, um cantor se apresentava ao vivo e convidou uma cantora para uma participação especial. Enquanto ela cantava, o microfone foi

97 Annabelle Sreberny e Gholam Khiabany, Blogistan: the Internet and Politics in Iran, Londres: I. B. Taurus, 2010; Sima Shakhsari, "From Homoerotics of Exile to Homopolitics of Diaspora: Cyberspace, the War on Terror, and the Hypervisible Iranian Queer", Journal of Middle East Women Studies, v. 8, n. 3 (2012), pp. 14-40 ש.

98 Bahramitash e Hooglund (orgs.), Gender in Contemporary Iran; Mansouri-Zeyni, "The History of Ressentiment".

99 Bahramitash e Hooglund (orgs.), Gender in Contemporary Iran; Small Media, LGBT Republic of Iran: an Online Reality? A Small Media Report Revealing How Iran's LGBT Communities Use Global Communicaitons Technologies in their Everyday Lives, Londres: Small Media, 2012.

100 Ah T, Happy we are from Tehran, 2014 C. 
cortado, pois mulheres não deviam cantar em público. Há uma lista de cantores proibidos, mas, segundo ela, as pessoas ouvem o que querem por terem acesso às músicas pela internet ou por canais a cabo. Em 2019, foi a vez de uma jovem artista iraniana ser interrogada pelas autoridades policiais e "levada" a confessar um "crime moral” depois de postar um vídeo em que aparecia dançando "sensualmente” sem véu. ${ }^{101}$ A internet serve também para divulgar as agressões sofridas por aquelas pessoas que são reprimidas quando estão transgredindo as normas e, assim, questionando heterotopicamente a utopia e a distopia. Ora, a poesia, a música, a dança e as artes em geral sempre marcaram fortemente a cultura persa e, agora, têm se configurado como um espaço de resistência e de proposição marcadamente heterotópicos na atualidade. ${ }^{102}$

Ao longo da segunda metade de 2010, através da internet, mulheres de algumas cidades iranianas se mobilizaram, uma vez por semana, para retirar publicamente seus véus e filmar essas manifestações-relâmpago (flash mobs). Muitos homens aderiram à mobilização em mais uma forma de constituição de heterotopias. Durante a crise sanitária internacional gerada pela pandemia de Covid-19, foi a vez dos profissionais de saúde, homens e mulheres, divulgarem vídeos em que apareciam dançando uniformizados, desafiando as autoridades policiais. Uma das passagens mais surpreendentes da conversa com Mehdi foi quando afirmou categoricamente que uma revolução feminina estava em curso: "Um véu que cai, uma maquiagem mais marcada, uma roupa mais justa, uma profissão inusitada, uma voz mais sonora...”. Logo depois, acrescentou que era a revolução pelos corpos que libertaria não somente as mulheres, mas todos os corpos rigidamente enquadrados pelas normas vigentes.

101 Cf. Journeyman Pictures, Dancing Tehran: Iran's Women Make a Stand, 2019 ש ou EuroNews, People show support for Maedeh Hozhabri was arrested after posting videos of herself dancing online, 2018 ש.

102 Davaran, Continuity in Iranian Identity; Ida Meftahi, Gender and Dance in Modern Iran: Biopolitics on Stage, Nova York: Routledge, 2016; Rahmieh Nasrin, Iranian Culture: Representation and Identity, Londres: Routledge, 2016. 


\section{Classificar, desclassificar e reclassificar}

Em julho de 2005, dois rapazes iranianos, condenados pelo estupro de um menor, foram enforcados publicamente. Embora não tenha sido confirmado, a mídia internacional, assim como diversas organizações de luta por direitos de pessoas homossexuais, alegaram que a punição era motivada pela orientação sexual dos rapazes. ${ }^{103} \mathrm{O}$ caso foi bastante divulgado nos Estados Unidos como um exemplo para justificar a guerra, por parte dos países ocidentais, ao terrorismo - reforçando a associação do islamismo à barbárie. ${ }^{104} \mathrm{~A}$ legislação iraniana prevê a pena capital para a prática sexual entre pessoas do mesmo sexo/gênero, mas há algumas condições que dificultam a condenação, como a necessidade de que o ato seja testemunhado por um certo número de pessoas. Isso faria com que, em alguns casos, as pessoas fossem denunciadas por outros crimes mais fáceis de serem punidos com a pena capital, muitas vezes motivados pelo simples ódio em relação às pessoas envolvidas ou como exemplos necessários para confirmar a biopolítica representacional hegemônica heteronormativa. ${ }^{105}$

Centenas de pessoas homossexuais teriam sido condenadas à morte no Irã desde a Revolução e milhares seriam vítimas de violência por serem afeminadas ou masculinizadas "demais", estarem maquiadas “demais” ou demonstrarem carinho “demais” em público. ${ }^{106}$ Não discutirei aqui o sistema jurídico iraniano, o que já foi feito com mais propriedade

103 Cf. Richard Kim, “Witnesses to an Execution”, The Nation, 7 ago. 2005 ש

104 Jin Haritaworn, Adi Kunstman e Silvia Posocco (orgs.), Queer Necropolitcs, Nova York: Routledge, 2014.

105 Afary, Sexual Politics in Modern Iran.

106 Iranian Railroad for Queer Refugees (IRQR), Iranian Queer Watch Report, Toronto: IRQR, 2018; Organização das Nações Unidas (ONU), Situation des Droits de l'Homme en République Islamique d'Iran: Rapport du Secrétaire Général, Nova York: ONU, 2019; 6 Rang - Iranian Lesbian and Transgender Network, Diagnosing Identities, Wounding Bodies: Medical Abuses and Other Human Rights Violations Against Lesbian, Gay and Transgender People in Iran, [s.l.]: 6rang; Justice for Iran, 2014 ש. 
por outros. ${ }^{107}$ Parto desses fatos para que se entenda a gravidade da prática sexual entre pessoas do mesmo sexo ou gênero no aparato jurídico-normativo iraniano, o que ratifica a importância dada pelo Estado ao controle heteronormativo dos corpos. Mesmo assim, algumas poucas pesquisas realizadas no Irã vêm mostrando a maneira criativa como o Estado é desafiado mediante heterotopias.

Najmabadi, numa pesquisa historiográfica rigorosa, mostrou como, ao longo do século XX, o Irã foi inserido na área de dominação ocidental, sendo levado a adotar a modernidade médico-científica e jurídico-moral europeia marcada por um regime biopolítico de verdade com base no dimorfismo sexual, no binarismo de gênero e na heterenormatividade. ${ }^{108} \mathrm{~A}$ autora documenta que, até então, as relações afetivas entre pessoas do mesmo sexo ou gênero eram triviais, baseadas na beleza dos jovens envolvidos e atreladas ao fato de que a segregação por gênero preservava o mundo dividido, incentivava a homossociabilidade e permitia que homens mais velhos mantivessem relacionamentos com rapazes mais novos, inclusive após o casamento, assim como mulheres pudessem declarar os "votos eternos de irmandade" a outras mulheres - contanto que em ambos os casos se agisse com circunspecção e se preservasse a prerrogativa da procriação. Os europeus passaram a se surpreender com as práticas sexuais persas, a ponto de, pouco a pouco, imporem, por meio de suas negociações econômicas e influência política, a moralidade moderna dos Estados-nações europeus. Segundo Najmabadi, assim consolidou-se, no Irã, o binarismo de gênero ou a oposição entre homens e mulheres como entidades biopsicológicas independentes, e concluiu-se a "heteronormalização do eros e do sexo", a "heterossocialização do espaço público" e a reconfiguração da vida

107 Elizabeth Bucar e Faegheh Shirazi, “The 'Invention' of Lesbian Acts in Iran: Interpretative Moves, Hidden Assumptions, and Emerging Categories of Sexuality”, Journal of Lesbian Studies, v. 16, n. 4 (2012), pp. 416-434 ש; International Gay and Lesbian Human Rights Commission (IGLHRC), Lesbian, Gay, Bisexual and Transgender Rights in Iran, [s.l.]: IGLHRC, 2015 C.

108 Najmabadi, Women With Mustaches and Men Without Beards. 
familiar com a introdução do amor entre um homem e uma mulher como condição para a constituição da família. ${ }^{109}$

Um pouco antes da revolução, relata-se que havia uma espécie de “cena gay” em Teerã, caracterizada por um conjunto de espaços de sociabilidade e uma certa visibilidade de pessoas identitariamente homossexuais, que também existia de forma mais tímida em outras cidades do país. ${ }^{110}$ As práticas sexuais entre pessoas do mesmo sexo ou gênero eram designadas por antigos termos empregados para as relações entre homens e entre mulheres vigentes antes do processo de modernização, mas começam, na segunda metade do século $\mathrm{XX}$, a ser designadas também por outros termos usados até os dias de hoje: hamjensbāzy foi um termo pejorativo forjado na década de 1960 a partir da vulgarização do discurso médico-científico para se referir ao ato sexual como um relacionamento predatório, ao passo que o termo, também negativo, hamjensgerāy apareceu na mídia, na década de 1970, referindo-se não ao ato sexual, mas aos sentimentos e desejos envolvidos na relação. ${ }^{111}$ Com a revolução, volta-se à segregação por gênero, ao banimento explícito da homossexualidade e à punição das práticas homossexuais. Em 2007, o então Presidente Ahmadinejad disse, nos Estados Unidos, respondendo sobre a execução de homossexuais no Irã, que não havia em seu país hamjensbāz, nem "esse fenômeno". ${ }^{112}$ Um ano depois, em outra entrevista, esclareceu que havia se referido à prática pública de hamjensbāzy, proibida, enquanto a prática de hamjensgerāy não lhe interessava, pois dizia respeito ao que as pessoas faziam secretamente. ${ }^{113} \mathrm{O}$ novo código penal iraniano de 2013 passa a usar o segundo termo, não mais o primeiro. ${ }^{114}$

109 Najmabadi, Women With Mustaches and Men Without Beards, p. 3.

110 Afary, Sexual Politics in Modern Iran; Kjaran, Gay Life Stories.

111 Bucar, “The 'Invention' of Lesbian Acts in Iran”; Kjaran, Gay Life Stories.

112 Cf. Ahmadinejad on the treatment of women and homosexuals, Nova York, 2007 ש.

113 Cf. Iranian President Mahmoud Ahmadinejad on Iran-Iraq Relations, Iran’s Persecution of Gays and the Future of Israel-Palestine, Democracy Now, 26 set. 2008 巴ש.

114 Kjaran, Gay Life Stories. 
Korycki e Nasirzadeh ${ }^{115}$ resumiram a constituição pública da homossexualidade no país assim: inicialmente, ao longo dos séculos XIX e XX, houve a heterossocialização do espaço social ${ }^{116}$ seguida, na segunda metade do século XX e no período imediatamente após a revolução, da proliferação das técnicas para "restaurar" os tipos desviantes por meio do direito e da medicina; ${ }^{117}$ e, enfim, a partir da década de 1990, com a entrada no país, via internet, dos discursos identitários e dos direitos humanos, teria havido a criação de um quadro mais positivo. ${ }^{118}$ Uma “revolução sexual” estaria em curso desde a década de 2000, segundo Afary, ${ }^{119}$ relacionada às transformações da vida familiar e das relações de gênero, por um lado e, por outro, às experiências da diversidade sexual com o impulso dado pela universalização da internet.

É nesse contexto que entra em cena o uso do termo "gay", como atestado por Kjaran e Martino, ${ }^{120}$ usado paralelamente ao termo hamjensgerāy. Surge um espaço transnacional e diaspórico de ativismo homossexual, ${ }^{121}$ com a criação, por exemplo, de grupos de apoio a pessoas homossexuais iranianas que deixaram o país. ${ }^{122}$ Desenvolve-se, também, de forma tímida mas bem articulada, um lócus de valorização da diversidade sexual e de gênero com, por exemplo, espaços de sociabilidade usados para encontros (residências privadas, parques, banhos e academias de ginástica homossociais etc.), sites e aplicativos discretos na internet e códigos vestimentares e corporais particulares que desafiam a polícia

115 Katarzyna Korycki e Abouzar Nasirzadeh, "Desire Recast: the Production of Gay Identity in Iran”, Journal of Gender Studies, v. 25, n. 1 (2016), pp. 50-65 600

116 Najmabadi, Women With Mustaches and Men Without Beards.

117 Najmabadi, Professing Selves.

118 Ahmad Karimi, "Iranian Homosexuals; Social Identity Formation and Question of Femininity”, Culture \& Psychology, v. 22, n. 2 (2016), pp. 296-313 बoo.

119 Afary, Sexual Politics in Modern Iran.

120 Jón Kjaran e Wayne Martino, in "Search of Queer Spaces in Tehran: Heterotopias, Power Geometries and Bodily Orientations in Queer Iranian Men’s Lives”, Sexualities, v. 22, n. 4 (2019), pp. 587-604 बㅇ․

121 Shakhsari, "From Homoerotics of Exile to Homopolitics of Diaspora”.

122 É o caso do International Railroad for Queer Refugees $飞$. 
moral e driblam a violência familiar, ${ }^{123}$ confirmados nas pesquisas de Kjaran e Martino. ${ }^{124}$ Enfim, completando essa paisagem heterotópica, aparece uma forma peculiar de ativismo que tenta criar uma imagem própria do modo como as práticas sexuais entre pessoas do mesmo sexo/ gênero funcionam e identificam pessoas no Irã, indo de encontro ao binarismo ocidental "homossexualidade versus heterossexualidade", para além daquelas imagens geralmente negativas divulgadas por ativistas ocidentais ou iranianos diaspóricos. ${ }^{125}$ Martino e Kjaran, Long, Kjaran e Mahdavi mostram como têm-se constituído, de forma bem particular, as experiências da diversidade sexual e de gênero no Irã baseadas nas categorias hamjensgerāy e "gay", contrárias a uma ideia universal de "homossexualidade". ${ }^{126}$ Em todos os casos, a internet desempenhou um papel fundamental no processo em andamento de produção de paisagens heterotópicas. ${ }^{127}$

Curiosamente, em paralelo a essa tensão entre o Estado e sua biopolítica heterormativa de segregação por gênero, de um lado e, de outro, as paisagens heterotópicas de experiências da diversidade sexual e de gênero contrárias aos padrões estatais impostos, o Irã é um dos países que mais faz cirurgias transsexualizadoras. Najmabadi alega que

123 IRQR, Iranian Queer Watch Report; Mohamadrasool Yadegarfard, "How Are Iranian Gay Men Coping With Systematic Suppression Under Islamic Law? A qualitative study”, Sexuality \& Culture, v. 23, n. 4 (2019), pp. 1250-1273 do․

124 Kjaran, Gay Life Stories; Kjaran e Martino, “In Search of Queer Spaces in Tehran”.

125 Ahmad Karimi, "Hamjensgara Belongs to Family; Exclusion and Inclusion of Male Homosexuality in Relation to Family Structure in Iran”, Identities: Global Studies in Culture and Power, v. 25, n. 4 (2018), pp. 456-474 6oi; Mitra Rastegar, "Emotional Attachments and Secular Imaginings: Western LGBTQ Activism on Iran”, GLQ: A Journal of Lesbian and Gay Studies, v. 19, n. 1 (2013), pp. 1-29 đol.

126 Wayne Martino e Jón Kjaran, “The Politics of Recognizability: Giving an Account of Iranian Gay Men's Lives Under Repressive Conditions of Sexuality Governance”, International Journal of Middle East Studies, v. 51, n. 1 (2019), pp. 21-41 बoi; Scott Long, "Unbearable Witness: How Western Activists (Mis)Recognize Sexuality in Iran”, Contemporary Politics, v. 15, n. 1 (2009), pp. 119-136 doi; Kjaran, Gay Life Stories; Pardis Mahdavi, "Questioning the Global Gays(ze): Constructions of Sexual Identities in Post-Revolutionary Iran”, Social Identities, v. 18, n. 2 (2012), pp. 223-237 doi.

127 Kjaran, Gay Life Stories; Small Media, LGBT Republic of Iran; Sreberny, Blogistan. 
a fatwa de Khomeini permitindo as cirurgias de redesignação sexual no Irã pós-Revolução foi mais um dispositivo biopolítico: por um lado, uma maneira de se opor ao regime monárquico e à ciência por ele sustentada e, por outro, a forma encontrada pelo governo islâmico para reforçar ainda mais a segregação por gênero e a heteronormatividade, ao permitir que homens e mulheres se adequassem ao gênero que lhes convinha e, assim, não reincidissem no "crime maior": a homossexualidade. ${ }^{128}$ Alguns pesquisadores apresentaram relatos de pessoas que se sentiram impelidas à cirurgia de redesignação para não correrem o risco de serem condenadas à pena capital, sendo forçadas por agentes do Estado, quando não pela própria família. ${ }^{129}$ Geralmente, essas pessoas desejam obter documentos que lhes permitam andar livremente pelos espaços públicos sem serem assediadas pela polícia moral. ${ }^{130}$ Ter os documentos assegura o direito de manter relações sexuais como desejado, o que acaba representando espaços e práticas heterotópicas, já que a cirurgia não necessariamente é a finalidade em si. ${ }^{131}$

As experiências da diversidade sexual e de gênero no Irã são objeto de intensa preocupação por parte de organismos internacionais de defesa dos direitos de pessoas homossexuais. Denunciando a aplicação da pena capital, a cirurgia de redesignação forçada ou o sofrimento gerado pela sociabilidade às escondidas, esses organismos são interpelados, por alguns pesquisadores, a levar em conta também as criativas formas particulares de se vivenciar as experiências da diversidade sexual e de gênero no contexto específico sob o governo da "espiritualidade política” - marcado por suas paisagens heterotópicas. Alguns autores chamaram atenção para

128 Najmabadi, Professing Selves.

129 Kjaran, Gay Life Stories; Najmabadi, Professing Selves.

130 Bucar, “The 'Invention’ of Lesbian Acts in Iran”.

131 Elizabeth Bucar e Anne Enke, "Unlikely Sex Change Capitals of the World: Trinidad, United States, and Tehran, Iran, as Twin Yardsticks of Homonormative Liberalism”, Feminist Studies, v. 37, n. 2 (2011), pp. 301-328 ש; Bucar, “The 'Invention' of Lesbian Acts in Iran”; Najmabadi, Professing Selves. 
o cuidado que se deve ter em relação ao "liberalismo homonormativo"132 transformado em "homonacionalismo", ${ }^{133}$ que prega uma certa universalidade transnacional das experiências homossexuais (LGBTQIA+) e denuncia as tecnologias biopolíticas estatais iranianas, muitas vezes desconsiderando as formas de ativismo locais, as agências dos sujeitos envolvidos e a inventividade de suas práticas singulares de enfrentamento às tecnologias opressoras. ${ }^{134}$

\section{Perspectiva: por uma outra “espiritualidade política”?}

O parágrafo anterior indica a relação entre o Estado e a sexualidade por meio da instauração das tecnologias de poder-saber da governamentalidade. Geralmente, consideram-se os Estados ocidentais como aqueles que defendem os direitos humanos e as liberdades individuais e promovem as identidades baseadas nas experiências da diversidade sexual e de gênero, em nome da ciência, enquanto os Estados “não ocidentais” são aqueles que barbaramente reprimiriam, pelo uso da força e em nome da religião, a diversidade. ${ }^{135}$

Os Estados nacionais modernos são produtos da colonização, segundo Balibar, já que todos foram colonizados ou colonizadores de alguma forma - ou os dois ao mesmo tempo. ${ }^{136}$ Universalizaram-se com o expansionismo europeu entre os séculos XVI e XX, com base, para Quijano e Wallerstein, na exploração - colonial, imperial e capitalista de uma maioria por uma minoria, por meio do controle bionecropolítico

132 Bucar, "Unlikely Sex Change Capitals of the World”.

133 Jasbir Puar, Terrorist Assemblage: Homonationalism in Queer Times, Durham: Duke University Press, 2007.

134 Haritaworn, Queer Necropolitics; Long, "Unbearable Witness"; Mahdavi, “Questioning the Global Gays(ze)".

135 Hamid Dabashi, Brown Skin, White Masks, Londres: Pluto Press, 2011.

136 Étienne Balibar, “La Forme Nation: histoire et idéologie” in Étienne Balibar e Immanuel Wallerstein (orgs.), Race, Nation, Classe: les identités ambiguës, Paris: La Découverte, 1988, pp. 117-143. 
dos corpos através dos regimes de verdade instituidores da ideologia e da hierarquia raciais, do binarismo de gênero e da heteronormatividade, dentre outros dispositivos sustentados por e sustentadores das discursividades médico-científicas e jurídico-morais ocidentais. ${ }^{137}$ Assim, a relação entre Estado e sexualidade mediada pelo controle social não seria exclusiva dos regimes políticos considerados pelos Estados ocidentais como opressores, mas estaria na base existencial de todos os Estados nacionais (inclusive ocidentais), sempre criadores de algum tipo de homo sexualis na origem do homo nationalis.

Analisando a obra de diversos autores que abordam a relação entre o Estado e a sexualidade, Puri percebeu a recorrência do tema da regulação efetuada pelo Estado sobre os mais diversos aspectos da vida privada ao delimitar os contornos das "sexualidades respeitáveis". ${ }^{138}$ Por se tratar de invenções euro-americanas ou ocidentais, o conceito de identidade sexual ganhou o planeta por meio do expansionismo europeu, com significados particulares a cada contexto cultural em razão das configurações locais das relações de poder definidoras da situação colonial persistente $\mathrm{e}^{139}$ - ou seja: dos regimes de verdade, dispositivos biopolíticos e mecanismos institucionais e ideológicos de controle social que determinam o que é "normal” e o que é “abjeto”, instituindo e reforçando as desigualdades de gênero, classe, raça etc. ${ }^{140} \mathrm{O}$ Estado se constituiu, na modernidade, com a ajuda da inclusão da vida humana nos mecanismos e cálculos de poder. A contradição está no fato de que o mesmo Estado que se compromete com a garantia da vida e da felicidade é, também, aquele que define categorias

137 Aníbal Quijano, “Colonialidad del Poder y Classificación Social”, Journal of World-Systems Research, v. 6, n. 2 (2000), pp. 342-386 बio; Immanuel Wallerstein, Comprendre le Monde: introduction à l'analyse des systèmes-monde, Paris: La Découverte, 2006.

138 Jyoti Puri, Encoutering Nationalism, Malden: Blackwell Publishing, 2004.

139 Ruth Vanita, Queering India: Same-Sex Love and Eroticism in Indian Culture and Society, Londres: Routledge, 2002.

140 Fabiano Gontijo, “Nation-Building, Gênero e Política no Cazaquistão”, Mana, v. 24, n. 3 (2018), pp. 151-185 ब0]. 
de pessoas matáveis e cria situações excepcionais para a matabilidade e para a invisibilização. ${ }^{141}$

Para existir enquanto instrumento de governo, que promove a felicidade para alguns ao mesmo tempo em que tem o poder de limitar seu acesso a outros, o Estado necessita de uma base simbólica que naturalize suas práticas de poder de modo a não ser questionado a respeito de uma possível ideologia nacional que outorgue sentidos às tecnologias de poder/ saber e dispositivos estatais.

O Irã é citado internacionalmente como o exemplo de país onde prevalecem as repressões sexuais por parte do Estado, imbuído da ideologia nacional de cunho religioso, quando comparado às sociedades euro-americanas, consideradas como paraísos libertários. Puar nos mostra que o homonacionalismo de países norte-americanos e europeus, por exemplo, pode ser uma falácia ocidental elaborada por políticos dos grupos dominantes para legitimar as suas intenções expansionistas, ao encamparem algumas reinvindicações identitárias de grupos LGBTQI+ e desenvolverem uma política representacional hegemônica como um forma de se mostrar mais "civilizados” em relação a nações acusadas, então, de “incivilizadas”. ${ }^{142}$ Mas, ao fazê-lo, nega-se totalmente as tensões internas relacionadas aos modos múltiplos de se experimentar a diversidade sexual e de gênero, e não se percebe o tratamento diferenciado dado pelo Estado, por meio do uso dos dispositivos biopolíticos, a essa multiplicidade, valorizando uma certa "sexualidade respeitável” em detrimento de tantas outras formas. É assim que o Irã da "espiritualidade política” teria virado, aos olhos do Ocidente, a nação, por excelência, da “barbárie”. 143

No Irã, onde a intencionalidade da ação bionecropolítica do Estado parece mais explícita do que em países ocidentais, as paisagens

141 Giorgio Agamben, Homo Sacer: Sovereign Power and Bare Life, Stanford: Stanford University Press, 1995.

142 Puar, Terrorist Assemblage.

143 Dabashi, Brown Skin, White Masks; Dabashi, Iran. 
heterotópicas descritas acima despontariam como formas sutis de questionamento da naturalização das práticas de poder do Estado, confrontando a própria ideologia nacional sustentada pela tal “espiritualidade política”. As heterotopias apresentadas não estão todas igualmente às margens do Estado nacional, mas permitem que se afirme, junto com Das e Poole, que “as práticas e as políticas da vida nessas áreas [marginais] moldaram as práticas políticas, regulatórias e disciplinares que constituem, de alguma forma, aquilo que chamamos de 'Estado'”. ${ }^{144}$ Fazer uma etnografia dessas "práticas e políticas da vida” marginais, ou seja, do Estado iraniano pelas suas heterotopias, foi a maneira que encontrei para tentar dar conta das formas e ações simbólicas que sustentam ideologicamente a ideia de nação pela negação da alteridade e pelo enquadramento da diversidade sexual e de gênero - o que acontece não somente no Irã, mas em todos os lugares onde o Estado nacional existe. As heterotopias raiariam como “estratégias de cidadania, imaginários tecnológicos e novas regiões da linguagem"145 que, mesmo contrariando a utopia da "espiritualidade política”, contribuem para a construção do Estado, já que é a existência dessas margens que garante a legitimidade do Estado como tal, definidor do "normal” e do "abjeto".

Quando grupos são patologizados e/ou criminalizados por tecnologias de poder/saber baseadas na "espiritualidade política” ou outra forma qualquer de legitimação do poder, não parecem se submeter passivamente, como mostrei, mas reagem criativamente mediante táticas de agenciamento heterotópicas - tais como um véu que cai pelas costas, o download de músicas proibidas, a fabricação clandestina de bebidas alcoólicas, a realização de festas privadas, o contrabando de literatura ilegal etc. Para que o Estado não perdesse o seu legítimo direito biopolítico sobre os corpos de cada indivíduo, acabou até mesmo legitimando, mediante uma

144 Veena Das e Deborah Poole, "State and Its Margins: Comparative ethnographies” in Veena Das e Deborah Poole (orgs.), Anthropology in the Margins of the State (Oxford: Oxford University Press, 2004), p. 3.

145 Das, "State and Its Margins”, p. 10. 
fatwa, a cirurgia de redesignação sexual, tornando-a inclusive desejável para alguns sujeitos homossexuais.

Ao longo do tempo, a opressão foi internalizada pelos iranianos, ${ }^{146}$ tornando-se, de fato, natural (enquanto é, na realidade, um efeito de poder socialmente estabelecido); acredita-se que o que está na base da opressão é absolutamente verdadeiro (enquanto é um arbitrário cultural) e aceita-se a discursividade hegemônica como única possibilidade existencial (enquanto há relações de poder subjacentes). O Estado faz vista grossa sobre certas práticas transgressoras (levando as pessoas a acreditarem que são livres para contestá-lo) ao mesmo tempo em que tenta enquadrá-las. O sistema assim acordado parece sustentar-se por tanto tempo precisamente porque as heterotopias são de conhecimento do Estado e, num aparente paradoxo, uma forma de agência contra o sistema. As heterotopias seriam um faz de conta que contribuiria com eficácia para a reprodução do status quo e a "espiritualidade política" do regime. As heterotopias, todavia, parecem, com base no que foi apresentado acima, manter a "espiritualidade política" enquanto sutilmente a substituem, pouco a pouco, por uma outra forma de "espiritualidade política”: elas poderão se tornar o topos hegemônico, como nova forma de utopia também baseada numa "espiritualidade política” caso o questionamento da distopia se agudize - o que ainda não aconteceu, talvez, em razão da manutenção do status quo cotidianamente negociado para manter o equilíbrio distópico entre a utopia do Estado bionecropolítico e as heterotopias dos processos da vida.

Até quando durará esse frágil equilíbrio, minuciosamente coestabelecido pelo Estado e suas instituições de controle e as pessoas em suas vidas cotidianas? Será até que se difunda essa outra "espiritualidade política" baseada numa nova "vontade coletiva perfeitamente unificada", ${ }^{147}$ aí sim, promissora de "o fim da dependência, o desaparecimento

146 Korycki, "Desire Recast”.

147 Foucault, Dits et Écrits II, p. 693. 
da polícia, a redistribuição da renda do petróleo, a caça à corrupção, a reativação do [verdadeiro?] Islã, um outro modo de vida, novas relações com o Ocidente, com os países árabes, com a Ásia etc.”, ${ }^{148}$ como profetizado por Foucault em 1978?

Recebido em 4 ago. 2020

Aprovado em 24 nov. 2020

doi: 10.9771/aa.v0i63.38245

148 Foucault, Dits et Écrits II, p. 715. 
No final da década de 1970, o mundo acompanhou os acontecimentos revolucionários que levaram à destituição da monarquia e à instauração de uma república islâmica no Irã. Michel Foucault viu nesses acontecimentos, caracterizados pela "espiritualidade política”, um potencial crítico à modernidade ocidental. Trata-se aqui de produzir uma reflexão sobre o impacto dessa "espiritualidade política" na construção de um Estado nacional baseado em tecnologias de poder/saber geradoras de distopia e conformadoras de uma ideologia nacional teocrática preocupada com o controle dos corpos e a imposição da heteronormatividade. Será possível, assim, abordar os modos criativos de resistência ao regime de verdade vigente e de produção de formas de subjetivação alternativas, principalmente no que diz respeito às experiências da diversidade sexual e de gênero. Esses modos compõem paisagens heterotópicas que desafiam a distopia reinante, como sugerido por minha experiência etnográfica no Irã em fevereiro de 2019.

Sexualidade | Estado | Nação | Heterotopia | Irã

\section{Gender and Sexual Diversity, National State}

and Heterotopic LANDSCAPE: Foucault AND BEyond

At the end of the 1970s, the world followed the revolutionary events that led to the end of the monarchy and the establishment of an Islamic republic in Iran. Michel Foucault saw these events, characterized by a "political spirituality", as a potential critic of Western modernity. This study presents a reflection on the effect of this "political spirituality" in the construction of a national State based on technologies of power/knowledge that generate a dystopia and shape a national theocratic ideology concerned with the control of bodies and the imposition of heteronormativity. This article shows the original ways of resistance established to counter the regime of truth and to produce an alternative way of being, especially regarding the experiences of gender and sexual diversity. These ways compose a heterotopic landscape that challenge the reigning dystopia, as suggested by observations in Iran in February 2019.

Sexuality | State | Nation | Heterotopia | Iran 